\title{
A Study of Future Communications Concepts and Technologies for the National Airspace System-Part I
}

\author{
Ms. Denise S. Ponchak and Mr. Rafael D. Apaza \\ NASA Glenn Research Center \\ Cleveland, OH, USA \\ Denise.S.Ponchak@nasa.gov \\ Rafael.D.Apaza@nasa.gov \\ Mr. Brian Haynes \\ Xcelar \\ Hopkins, MN, USA \\ brian.haynes@xcelar.com
}

\author{
Mr. Joel M. Wichgers \\ Rockwell Collins \\ Cedar Rapids, IA, USA \\ jmwichge@,rockwellcollins.com
}

\author{
Mr. Aloke Roy \\ Honeywell International, Inc. \\ Columbia, MD, USA \\ aloke.roy@honeywell.com
}

\begin{abstract}
The National Aviation and Space Administration (NASA) Glenn Research Center (GRC) is investigating current and anticipated wireless communications concepts and technologies that the National Airspace System (NAS) may need in the next 50 years. NASA has awarded three NASA Research Announcements (NAR) studies with the objective to determine the most promising candidate technologies for air-to-air and air-to-ground data exchange and analyze their suitability in a post-NextGen NAS environment. This paper will present progress made in the studies and describe the communications challenges and opportunities that have been identified during the studies' first phase.
\end{abstract}

\section{TABLE OF CONTENTS}

1. INTRODUCTION. ERROR! BOOKMARK NOT DEFINED.

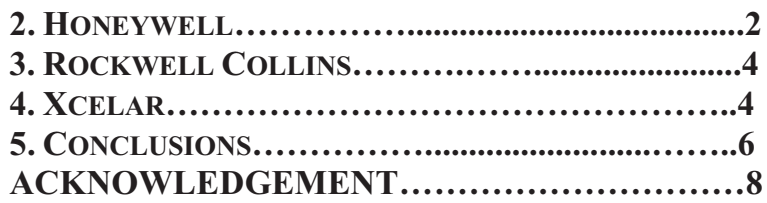

\section{INTRODUCTION}

NASA's NextGen Concepts and Technology Development (CTD) Project integrates solutions for a safe, efficient and high-capacity airspace system through joint research efforts and partnerships with other government agencies. The CTD Project is one of two within NASA's Airspace Systems Program and is managed by the NASA Ames Research Center. Research within the CTD Project is in support the 2011 NASA Strategic Plan Sub-Goal 4.1: Develop innovative solutions and advanced technologies, through a balanced research portfolio, to improve current and future air transportation. The focus of
CTD is on developing capabilities in traffic flow management, dynamic airspace configuration, separation assurance, super density operations, and airport surface operations. Important to its research is the development of human/automation information requirements and decision-making guidelines for human-human and human-machine airportal decision-making. Airborne separation, oceanic in-trail climb/descent and interval management applications depend on location and intent information of surrounding aircraft. ADS-B has been proposed to provide the information exchange, but other candidates such as satellite-based receivers, broadband or airborne internet, and cellular communications are possible candidate's. For further information, the CTD project plan can be found at: http://www.aeronautics.nasa.gov/pdf/ctd project plan_2011_5 08.pdf

In the Spring of 2012, NASA Ames Research Center issued an amendment (CTD1 Subtopic 3) entitled: "Technology Candidates for Air-to-Air and Air-to-Ground Data Exchange" calling for proposals to NASA Research Announcement (NRA) "Research Opportunities in Aeronautics", NNH11ZEA001N. Future applications such as airborne separation, oceanic in-trail climb/descent and interval management depend on the location and intent information of the surrounding aircraft with respect to an aircraft. Presently, Automatic Dependent Surveillance Broadcast (ADS-B) technology has been proposed to receive that information. However, satellite-based receivers, broadband or airborne internet, and cellular communications have also been proposed as possible candidates. The purpose of this solicitation was to identify the air-to-air and air-to-ground communication methods for NextGen and beyond NextGen operations. The specific goals are as follows:

1. Identify existing or emerging technology candidates (and their integration), including but not limited to ADS-B, suitable for air-to-air and air-to-ground communications over a NAS modernization horizon of 50 years. 
2. Quantify the functional attributes and characteristics of each candidate, including (but not limited to) communications range, bandwidth, latency, integrity, reliability, and security.

3. Map the technology candidates to specific air traffic management applications where they will be most beneficial and cost effective.

4. Identify the infrastructure and architecture needs of the potential technologies for air-to-air and air-to-ground exchange.

5. Identify rough magnitude cost estimates, or relative cost comparisons, and any technological characteristics such as bandwidth, and reliability.

6. Provide assessment of how these technologies could be used for air traffic management applications including but not limited to airborne separation and interval management.

7. Identify vulnerabilities and security issues and mitigation of any proposed concepts.

The proposer was asked to identify current and future technologies that would be useful for air-to air and air-toground information exchange related to air traffic management applications. This was an exploratory NRA subtopic and there was flexibility for the proposer to select an appropriate approach. The anticipated duration was 24 months from the date of the award. The expected outcomes, deliverables, and, schedule were defined as follows:

1. A report describing technology candidates (and their integration) that will allow air-to-air and air-to-ground data exchange. Describe strengths and weaknesses of each. The report should include but not be limited to how the ADS-B could be made more cost effective. (Q3)

2. A report documenting infrastructure and architectural needs of these identified technology candidates. (Q4)

3. A report describing comparison of multiple alternatives and/or their integration based on costs, bandwidth, safety, reliability and security to support air-to-air and air-to-ground communications appropriate for future air traffic management operations. (Q5)

4. A report describing alternative technologies, their integration, dependencies on infrastructure and their potential use for air traffic management applications including but not limited to airborne separation and interval management. (Q7)

5. A detailed description of most promising technology alternative(s). (Q8)

The proposals were due on April 3rd, 2012. NASA Glenn Research Center led the evaluation of submitted proposals. In September 2012, three contract awards were made. They were: A Study of NAS Data Exchange Environment through 2060 (Honeywell, Columbia, MD, Aloke Roy/PI); NASA Com50 (Rockwell Collins, Cedar Rapids, IA, Joel Wichgers/PI); and, Technology Candidates for Air-to-Air nd Air-to-Ground Data Exchange (Agile Defense LLC, Hopkins, MN, Brian
Hayes/PI). These three studies all began in October 2012 and have a 24 month duration. This paper provides a summary of approximately the first six months of effort for each study.

\section{HONEYWELL}

\section{BACKGROUND}

Honeywell has been studying communication technologies suitable to support future Air Traffic Management needs in the 2060 time frame. The study was sponsored under NASA's Next Generation (NextGen) Concepts and Technology Development (CTD1) project, sub-topic area-3: Candidates for Air-to-Air and Air-to-Ground Data Exchange. This section summarizes Honeywell's initial findings to characterize candidate technologies for "Beyond NextGen" communications.

\section{HoneYWELl TeChNicAl APPROACH}

The technical approach started with the characterization of existing, upcoming and embryonic communication technology candidates. These technologies were identified by literature survey of public domain information, including standards, specifications, research papers and reports published at various forums around the World. Through the course of the project, increasingly fine filters were applied through objective, criteria-based analyses and assessments. For example, a filter eliminated candidates that do not meet basic ATM needs and criteria. Those criteria were derived from ICAO Global Navigation Plan and Communications Operating Concepts and Requirements (COCR), which was jointly defined by Eurocontrol and the United States Federal Aviation Administration (FAA). Successive filters examined architectural impacts and costs to ascertain the best value alternatives from the initial set of technology candidates. This report summarizes the findings of Honeywell after the candidate technology characterization. Subsequent publications will report the results of architectural, cost and operational analyses.

\section{COMMUNICATION ENVIRONMENT IN 2060}

NextGen represents a paradigm shift from rules-based to performance-based operations in the NAS, and data exchanges are a key enabler to achieve reduced aircraft separation and efficient movements in a more dense and dynamic airspace environment. As needs for situational awareness, airspace avoidance, and weather avoidance information increase with more complex and dynamic operations, advanced communication technologies coupled with innovative and cost-effective applications of existing technologies will be necessary to meet the required performance objectives. Communication beyond NextGen is expected to be multifaceted whereby airborne platforms maintain multiple communication channels simultaneously with other terrestrial and airborne platforms to meet the availability, integrity and continuity of service requirements for autonomous operations. 


\section{Candidate Technology Analysis}

\section{Current Technologies}

Current communication technologies for aviation include dedicated HF, narrow-band VHF systems; shared low-speed satellite systems such as INMERSAT Classic and IRIDIUM; and IEEE 802.11 wireless systems operating on shared Industrial, Scientific and Medical radio spectrum. These legacy systems will not meet the stringent performance requirements of the ATM systems Beyond NextGen.

\section{Emerging Technologies}

The US and Europe defined the Future Communications Infrastructure (FCI) for safety critical communications in the 2020 timeframe and beyond. The FCI identified AeroMACS (Aeronautical Mobile Airport Communications System) based on the IEEE 802.16 standard for airport terminal area, L-band systems for terrestrial enroute and next generation satellite systems for oceanic, remote and polar regions.

In addition to the above, some emerging commercial technologies targeting passenger communications are also under various stages of development. These technologies include 4G/5G cellular, Swift Broadband, IRIDIUM Next, $\mathrm{Ka} / \mathrm{Ku}$ band SATCOM, and other commercial satellite based technologies. Some of these technologies, for example $4 \mathrm{G} / 5 \mathrm{G}$ cellular and $\mathrm{Ka} / \mathrm{Ku}$ band SATCOM, will evolve with the commercial market and will continue to serve the future needs. Some others, such as L-band and VHF may remain in place to satisfy very specialized aviation environments and services.

\section{Embryonic Technologies}

Free space optical (FSO) communication is the most notable embryonic technology to consider for the aviation environment. X-Ray is an extension of the FSO. However, XRay communications requires very high power and therefore mostly effective indoors over short ranges.

It is anticipated that the dominant challenges of FSO, which are atmospheric attenuation and signal acquisition and maintenance from high-speed, mobile platforms will be mostly mitigated over the next fifty years. Therefore, FSO will be a viable technology candidate for Beyond NextGen aviation while X-Ray may still be limited to indoor usage where highpower radiation may not be required.

\section{Evaluation Criteria}

The communication performance requirements for the technology elements were derived from the Future Radio System (FRS) in the Communications Operating Concept and Requirements (COCR) document. Specifically, the COCR Phase 2 worst case loads in 2030 were used as the initial values and they were escalated at an annual rate of $2.5 \%$ over 30 years to derive the loads for year 2060 timeframe. Subsequently, those loads were used as basis for establishing the evaluation criteria for latency, continuity, integrity and availability.

\section{Technology Characterization}

The technology candidates were assessed by comparing their performance against the needs of various aeronautical services. A weighted score card was developed that normalized the performance of the technologies in various airspaces to meet the critical needs defined under the evaluation criteria. Then a final score for each technology was obtained by summing its weighted scores and then the technology candidates were ranked based on their final scores.

For the purpose of this analysis, some of the critical NextGen ATM applications involving Trajectory Based Operations, Separation Assurance procedures including Interval Management, In-Trial Procedures, Crossing and Passing, Continuous Descent Approach, FIS services and SWIM applications are considered and the results are extrapolated for the overall requirement.

Figure 1 and Figure 2 show the ranking of the technology candidates to meet the critical air-to-air and air-to-ground ATM applications respectively. From pure technology perspective, it can be observed that broadband VHF clearly outranks all other technologies to support air-to-air surveillance services. On the other hand, multiple technologies will be suitable for the air-to-ground environment and a hybrid technology solution may be desired to cover all the services in all applicable airspaces.

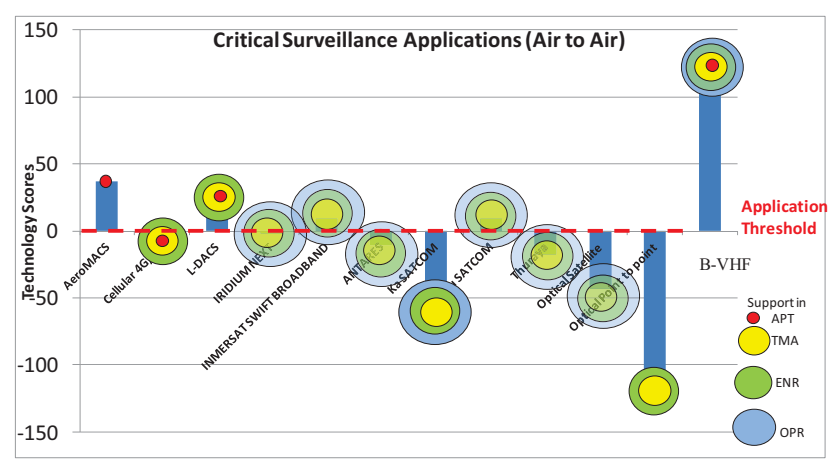

Figure 1. Technology capability scores for Air-to-Air Networking

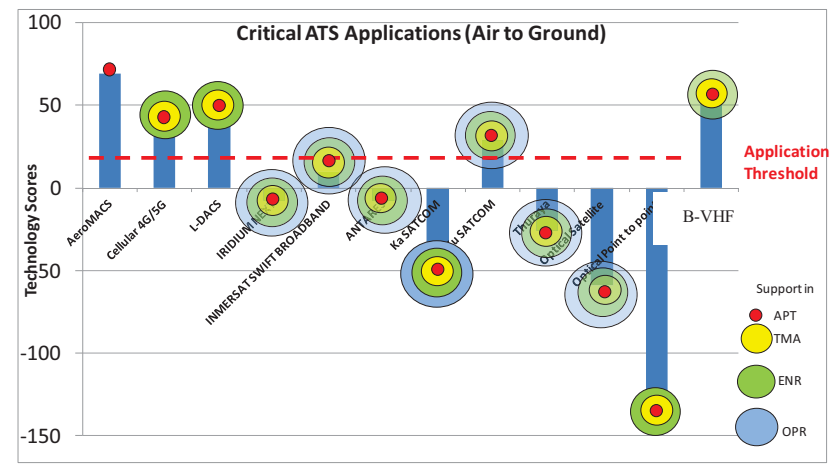

Figure 2. Technology capability scores for Air Ground Datalink 


\section{CONCLUSIONS \& RECOMMENDATIONS}

There are several good technology candidates to support air/ground services for transition through NextGen and several great choices in the year 2060 time frame. In the near term, AeroMACS is the clear winner for the APT region. L-DACS and ANTARES are preferred alternatives for TMA, and ENR, while ANTARES would be the choice for the ORP region. These near-term technology solutions present better options for NextGen ATM because they have been designed to support high-reliability, safety services. As the demand for higher volume data transfer grows over the time horizon, cellular $4 \mathrm{G} / 5 \mathrm{G}+$ technologies will be the preferred technology candidates for APT, TMA, and ENR regions. Similarly, Kuband satellite technologies may become better options for high-throughput data services beyond NextGen. FSO technology offers very high throughput, low latency and inherent communication security. The reliability and availability of FSO will be lower than other technologies in the APT and TMA regions due to atmospheric attenuations and other potential health hazards.

\section{NEXT STEPS}

The communication architectures for the leading technology candidates will be developed in the next step to further analyze their potential for ATM over the next fifty years. The architectures may include a specific technology, such as L-DACS, or it could be a hybrid consisting of two technologies, such as FSO and cellular.

A cost tradeoff analysis will be performed after a set of architecture alternatives have been identified to evaluate the relative cost impact for the aeronautical industry to migrate to the chosen architecture. The cost estimates will be a high level, relative approximation and will factor in the ramifications of shared versus dedicated infrastructure development.

In Phase-II of the NASA CTD1 contract, a simulation model will be developed to assess the performance of the proposed technology architecture against the projected performance requirements and utilize existing NASA traffic flow model to extrapolate NAS ATM environment to the year 2060 time frame.

\section{RockWELl COLlins}

\section{Background}

Today's National Airspace System (NAS) has served the community well in meeting past operational and safety needs. It has made effective and prudent use of air-routes, procedures, and traditional Communication, Navigation, and Surveillance systems to provide a level of capacity that was sufficient for the demand while maintaining a strong safety record. However, without change, the NAS will be unable to realize the capacity, efficiency, safety, security, and environmental improvements that are being demanded for the Next Generation Air Transportation System (NextGen) and beyond. To realize these improvements, the long term NextGen and beyond infrastructure is envisioned to be built on better, more capable, and optimally integrated communications, navigation, surveillance, information management, and decision support systems.

Communications, including both Aircraft-to-Aircraft (A-A) and Aircraft-to-Ground (A-G), is a key infrastructure element necessary to realize the future NAS vision such that the appropriate information is available at the required quality of service to enable the Air Traffic Management (ATM) systems to better utilize the airspace through enhanced operational procedures and applications.

\section{Today's NAS Communications}

Today's A-A and A-G NAS ATM-relevant communications are rather limited and consist primarily of VHF, HF, and SATCOM which support the traditional communications services, plus the use of L-band (978, 1030, and $1090 \mathrm{MHz}$ ) to support a number of surveillance and flight information services.

Emerging is the use of $1090 \mathrm{MHz}$ Extended Squitter and $978 \mathrm{MHz}$ Universal Access Transceiver (UAT) for A-A and AG Automatic Dependent Surveillance - Broadcast (ADS-B) and the A-G communications of companion traffic surveillance systems including ADS-Rebroadcast (ADS-R) and Traffic Information Services - Broadcast (TIS-B). Also, emerging or soon to emerge is the use of VHF data link (VDL) to support data communications between air traffic controllers and aircraft as well as the use of VHF Data Broadcast (VDB) to support GPS/Local Area Augmentation System (LAAS) Category I precision approaches.

\section{Long Term Future NAS Communications}

Future concepts of operation for the long term national air transportation system within the study 50 year time horizon include incorporating new types of aircraft as well as advanced operating procedures and applications that will drive the need for more A-A and A-G communications, especially data communications, at quality of service levels appropriate for the intended operations. Better communications will enable applications that enhance flight operations during all phases of flight. Examples of such future ATM applications that will be enabled or improved with enhanced communication capabilities include In-Trail Procedures (ITP), Interval Management (IM), Delegated Separation (DS), 4D Trajectory Based Operations (TBO), more highly optimized arrivals and departures, cruise climb, closely spaced parallel-runway operations (CSPO), simultaneous runway operations, and a next generation airborne collision avoidance system (ACAS$\mathrm{X}$ ). Examples of new aircraft types anticipated to be integrated into the NAS during the study time horizon include a wide range of Unmanned Air Vehicles (UAV), single piloted commercial aircraft, high speed transport vehicles, and commercial space-launched vehicles.

\section{Candidate Considerations}

A number of A-A and A-G communications technology candidates have been identified considering at least the following factors: 
- the physics of electromagnetic wave propagation through the atmosphere,

- wireless communications being used or under development for other applications (e.g., cellular, military, commercial broadband),

- communications currently in various stages of R\&D (e.g., free space optical communications),

- communication trends,

- technologies relevant to significantly improve wireless communications that are anticipated to mature during the study 50 year time horizon,

- the potential availability of spectrum,

- $\quad$ the ability to meet the anticipated NAS operational, performance, safety, and security requirements,

- the transition path between today's NAS communications and the future, and

- directions being taken by relevant regulatory (e.g., FAA, FCC, ITU) and industry standards groups (e.g., ICAO, RTCA, EUROCAE).

\section{Strategies for Addressing Long Term NAS Communication Needs}

The study has identified five fundamental strategic approaches for addressing the long term NAS communication needs including:

1) Reduce the need for communications bandwidth (e.g., using techniques such as data compression),

2) More efficiently using existing aviation communications spectrum (e.g., using higher order modulations),

3) Leverage commercial communications networks to support NAS communications needs,

4) Identify and reuse existing "aviation" spectrum to support NAS communications [e.g., use of portions of the "navigation" spectrum, including portions of the VHF (VOR spectrum), C-Band (MLS spectrum), and L-band (DME spectrum) to support NAS “communications"], and

5) Identify and obtain new spectrum allocations for NAS communications.

\section{Candidates}

A-A and A-G communication candidates have been identified with due consideration given to the aforementioned factors and strategies. Figure 3 and Figure 4 list current and future Air-to-Air and Air-to-Ground communication candidates, respectively, identified as part of the study. A-A candidates include line-of-sight (LOS) candidates including VHF, UHF, L-band, and optical as well as one hop routing through future SATCOM satellites. A-G candidates include LOS candidates from VHF to optical, as well as beyond LOS candidates that include HF, SATCOM, and A-G communications enabled by A-A hopping. Additional A-A and A-G communication candidates have been identified and evaluated as part of the study that have not been depicted in the figures below.

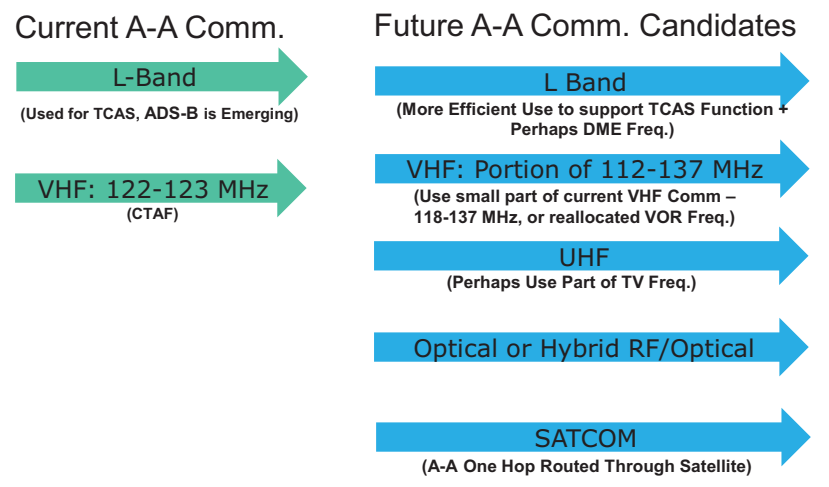

Figure 3. Air-to-Air Communications

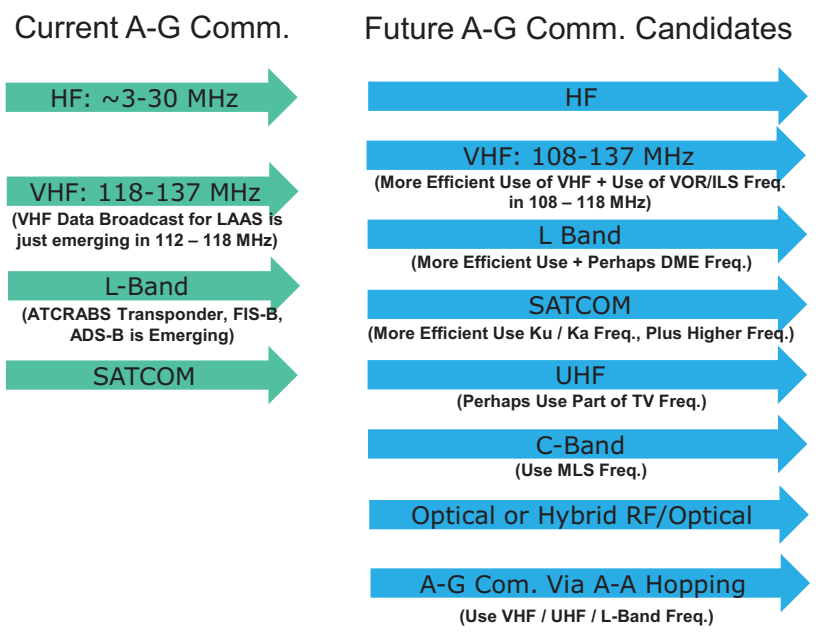

Figure 4. Air-to-Ground Communications

\section{Interim Study Findings}

As part of the study, each of the A-A and A-G candidates has been characterized as to the communication bandwidth, latency, communications range, expected user data rates, capacity, link spectral efficiency, availability, coverage, vulnerabilities, advantages, disadvantages, and technology readiness. The candidates have also been mapped to current and expected future airspace ATM applications where they will be most beneficial and cost effective. While the presentation of all the results from these assessments is beyond the scope of this paper, a summary of the interim study findings resulting from these assessments is provided below.

- Current A-A and A-G NAS communications links are insufficient to meet the anticipated future needs of the NAS.

- The future NAS will require significantly more A-A and A-G communications to support the envisioned NAS NextGen and beyond operations as envisioned in the JPDO Concept of Operations. 
- Traffic is expected to increase $3 \mathrm{X}$ to $10 \mathrm{X}$ from today's NAS traffic levels over the 50 year study time horizon, assuming a yearly nominal growth rate between $2.2 \%$ and $4.7 \%$.

- Spectrum is a very limited resource. Allocation of it among all those who desire to use the spectrum is becoming increasingly more difficult. Many existing users of the spectrum (including aviation) will over time need to modernize their systems to improve their spectral efficiency to enable the spectrum to meet the future demands.

- Current spectrum efficiency of today's NAS A-A and A-G communications is inefficient by today's state of the practice for wireless communications.

- Wireless communications technologies are advancing in a number of areas that will lead to significant increases in the spectral efficiency (e.g., bits/Hz).

- The current state of the art for wireless communications achieves $\sim 60 \%$ of Shannon's channel capacity limit. $60 \%$ to $70 \%$ of Shannon's channel capacity limit will likely become the state of the practice for wireless communications systems during the modernization time horizon.

- It is envisioned that commercial broadband communication networks will expand beyond what is offered today to further support ATM communications (primarily A-G, but also A-A).

- Technology will advance over the study modernization time horizon that will enable SATCOM to efficiently use RF frequencies in the K, $\mathrm{V}$, and $\mathrm{W}$ bands (frequencies up to $\sim 110 \mathrm{GHz}$ ) not including frequencies around $60 \mathrm{GHz}$, in addition to the $\mathrm{Ku}$ and $\mathrm{Ka}$ bands used today.

- Technology will advance over the study modernization time horizon that will enable use of free space optical communications for ground to satellite, satellite to aircraft, aircraft-to-ground, and aircraft-to-aircraft communications.

- Future SATCOM communication systems are anticipated to be capable of allocating communication bandwidth (BW) and quality of service (QOS) on demand to support a wide range of applications, including those in civil aviation.

- Future Aviation CNS needs will evolve during the 50 year NAS study time horizon. NAS data communications can potentially reuse aviation spectrum that is decommissioned by other NAS services. The primary opportunities identified include: 1) the MLS C-band, 2) portions of the VHF VOR/ILS Localizer bands, and 3) portions of the DME (L band).

- Obtaining significantly more spectrum allocations dedicated to support NAS A-A and/or A-G communications will become increasingly challenging.

- Five fundamental strategic approaches have been identified for addressing the long-term NAS communication needs as described in this paper.

- As future NAS communication and information systems become more networked and provide a variety of information for enabling better airspace utilization digitally, there is the potential for increased cyber-attacks similar to those experienced by state and corporate information systems.

- Future NAS communications systems will need to address a variety of information security challenges. The successful implementation of information security will require coordination and collaboration between traditional aeronautical stakeholders (e.g., airlines, aircraft manufacturers, avionics suppliers, ground systems suppliers, aeronautical service providers, FAA/aviation authorities) and information security and information technology experts.

- The future communications infrastructure and architecture needs to be considered in the context of the overall NAS systems infrastructure and architecture such that the entire NAS infrastructure can be optimized while satisfying the operational, performance, safety, and security requirements.

- No one single communications data link technology can meet all the expected future A-A and A-G communications requirements for the NAS. A combination of various communication technologies will be needed to address the diverse aeronautical communications requirements across all the operational flight domains.

- The emerging and the predicted future communication technologies are envisioned to be able to meet the NextGen and beyond NAS aircraft-toaircraft and aircraft-to-ground communication needs.

Additional R\&D continues to be worked to more comprehensively identify, characterize, and evaluate how the A-A and A-G candidates could potentially serve the evolving long-term needs of the NAS.

\section{XCELAR}

The XCELAR Team approached the study more from an operator-oriented perspective than that of the equipment, service suppliers, or the ANSP. An important initial step involved defining the potential nature and capabilities of the air vehicles (manned, reduced-crew, or unmanned) and of the airspace system, in the context of benefits to the aircraft operator. A system-based model was used, with initial analysis using general functional roles (i.e., "Air Vehicle", "Groundbased ATM", "Ground-based Non-ATM" roles, and "To/From Vehicle", To/From Ground-based ATM", etc. for information flow) to define systemic capabilities, needs, and information flow decoupled from the current paradigm. Those system capabilities were then used to define the communication 
capabilities required for realization, from which future data link functional requirements were derived for use in a parallel study of various candidate link technologies, topologies, and architectures. A "form follows function" approach can then be applied to the candidate link analysis, in which specific link methods and combinations of methods serve the overall needs of the system in optimized ways.

As part of this definition of the future operational environment, a Future NAS Communications Workshop was held to help define NAS Scenarios using a wider team from industry, academia, NASA, and others. Four baseline scenario types were defined: Terminal Operations - Departures; En route Operations; Terminal Operations - Arrivals; and Ground Operations. Definitions for each scenario included top-level goals, primary success criteria, and expected capabilities \& needs. Future capabilities of both the vehicles and the National Airspace System (NAS) were considered, and operation types included Air Transport, including the use of reduced-crew configurations and unmanned vehicles; General Aviation and Business Aviation operators (including Very Light Jets); and other types of Unmanned Aerial Vehicle (UAV) operations. It is worthy of note that a significant level of reduced-crew and/or unmanned commercial operations was projected for the air transport sector.

A key consideration was to correctly define the underlying assumptions for the air transportation system of 50 years in the future, particularly in terms of regulatory considerations, system user expectations and sensitivities, and their rate of evolution over the 50-year period. One useful input to that process was to look back a similar period, and assess the rate of change over the past 50 years in the same industry. Examples of significant technical events approximately 50 years ago include:

- 1963 - B727 first flight

- 1963 - Cessna 336 enters service; 1965 - Cessna 337 in certification

- 1963 - Lear 23 first flight

- 1967 - B737 first flight

- $\quad$ SELCAL entered service approximately 50 years ago

30 years ago:

- 1983 - First cellular telephone received FAA approval (Motorola DynaTac)

- 1983 - First PDA (Psion 1); 1993 - Apple Newton

- $\quad$ ACARS Entered service

In that period of time, regulatory processes have adapted to accommodate a host of new technologies, including composite aircraft, glass cockpits, GPS, ADS-B, and many others. System users have accepted cellular communications, the Internet, PDAs, pervasive wireless connectivity, and increasing reliance on robotics (including unmanned surface transportation such as trams), and innumerable other technologies. The perspectives, capabilities, and adaptation of both regulators and users can be expected to continue to progress at similar or faster rates going forward. As a result, the "Future NAS" underlying assumptions included the premise that future regulatory processes will evolve to accommodate approval and use of the technologies available, and that system users will be prepared to accept an increasing level of connectivity, communication-dependent functionality, and robotics in the future air transportation system.

To minimize replication of previous efforts, an initial Literature Review of documents from NASA, AIAA, RTCA, IEEE, MITRE/MIT, FAA, Eurocontrol, ICAO and others was conducted at the beginning of the study. This review revealed limited applicable study work in past 10-15 years; the majority of work reviewed pertains to already-identified link technologies and/or NAS concepts, rather than future concepts. Most documents are focused on specific link technologies and their capabilities, rather than on future NAS functions and unmet communication needs. Little analysis was found of link-independent, result-based data delivery concepts rather than specific links for each purpose. Based on those findings, the approach of defining the future NAS, then functions/unmet needs, then delivery solutions, was selected as the overall study methodology.

In parallel with the future NAS definition and derivation of communication functions and requirements, an initial analysis of currently known link technologies was conducted to assess their current and probable future capabilities compared to projected loads and other factors. This "look forward" analysis provides a starting point in the identification and analysis of future solutions, and quantifies potential unmet needs in current systems, and therefore functions that will require new solutions. An example is the current use of $1030 / 1090 \mathrm{mHz}$ for ATCRBS, ADS-B, TCAS, and other proposed functions such as air-to-air linking of wake turbulence data. Initial analysis suggests that the current system will reach its capacity limit well before the 50-year future point, and alternate solutions must be considered as part of the study.

The next phase of the study includes the convergence of the parallel analyses of functional needs and candidate link solutions. The continued use of a system-based approach is planned; for example, a promising consideration for potential solutions may be the overall delivery performance of the system, not necessarily of a specific, purpose-developed link. The potential for a "delivery manager" function to aggregate multiple link capabilities, and manage not only message routing but required communication performance, with access to (or even control of) all layers of the each link's operation, offers a potential system solution where individual links may not meet the technical and business case needs of all stakeholders.

\section{Conclusions}

A NASA Research Announcement (NRA) study to investigate potential future aeronautical communication technologies that could serve aviation in the 2060 time frame was awarded in 2012. This NRA study is a one-year effort with an option that has been exercised for an additional year extension. The objective of this study is to investigate future air-ground communications technologies, evaluate possible 
architectures, assess future communication needs, and identify challenges that will need to be addressed in the development and implementation of such potential systems. An important element of the study is to consider technological and Air Traffic Management advances planned for implementation by the NextGen and SESAR programs. NASA awarded the study to Rockwell Collins Corporation, Honeywell Corporation and Xcelar Corporation to independently conduct the study. This paper provides results obtained to date by each company.

Preliminary findings indicate that spectrum and technology certification will continue to pose a challenge, especially in areas where software is increasingly used to perform hardware functions. It is anticipated that although some spectrum will become available as a result of the decommissioning of technologies i.e. VOR, the demand for spectrum will increase and future technologies will need to provide the ability to maximize the use of finite spectrum resources. Advances in electronics and communications technology will enable the integration of services and applications and thus reducing the number of system deployed to the aircraft. Finally, the future aviation radio technology will depend on numerous factors including: air traffic management procedures, airline operations business models and the configuration of the airspace, which is anticipated to include Unmanned Aircraft Systems, hypersonic flights and manned aircraft.

\section{ACKNOWLEDGMENT}

The authors would like to acknowledge the funding and support of the NASA Aeronautics Research Mission Directorate's Airspace Systems Program Office at NASA Headquarters and NASA Ames Research Center; specifically: Dr. John A. Cavolowsky, Dr. Parimal H. Kopardekar, Mr. Rudolph A. Aquilina, and, Ms. Nazaret C. Galeon. 


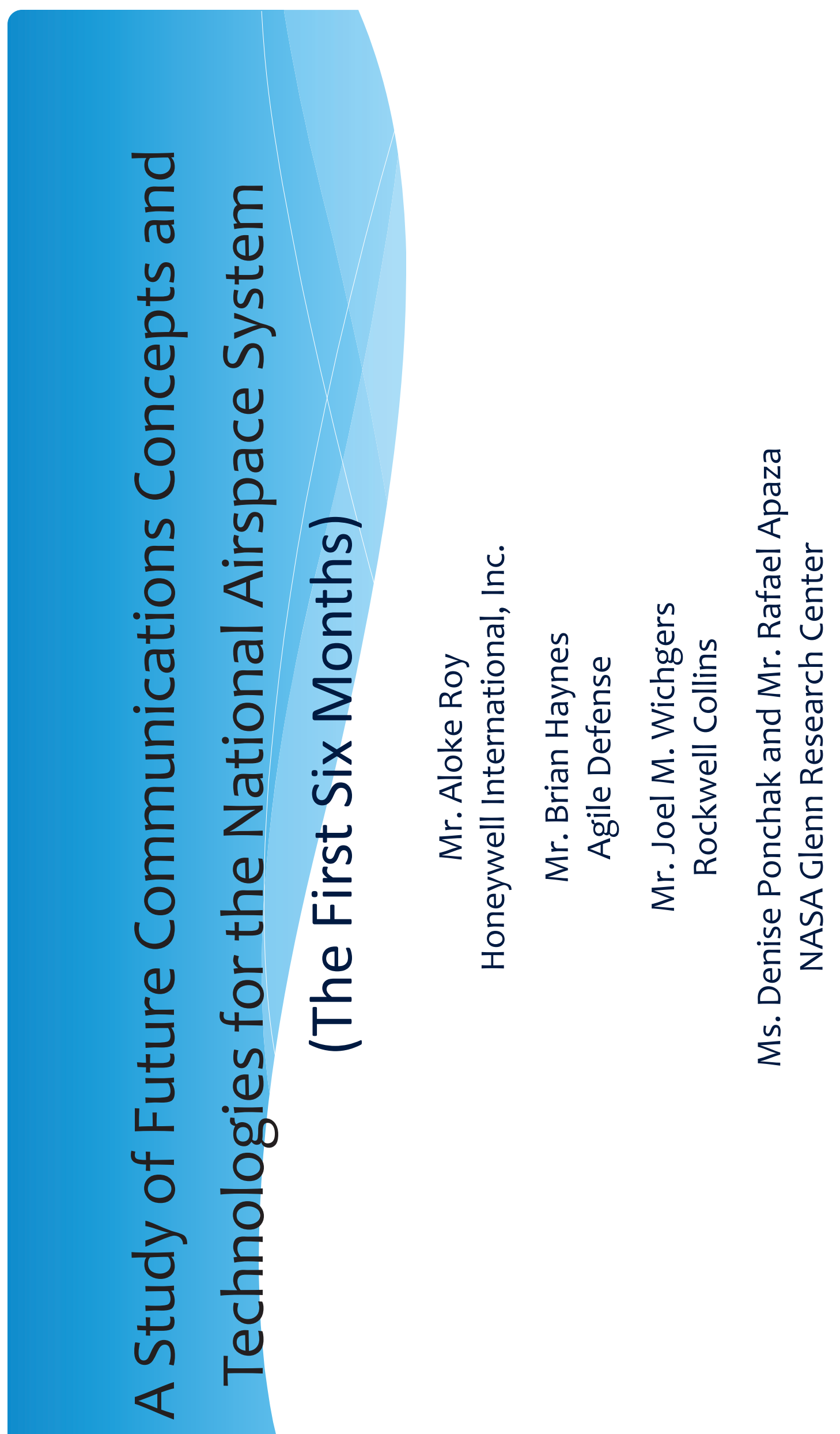




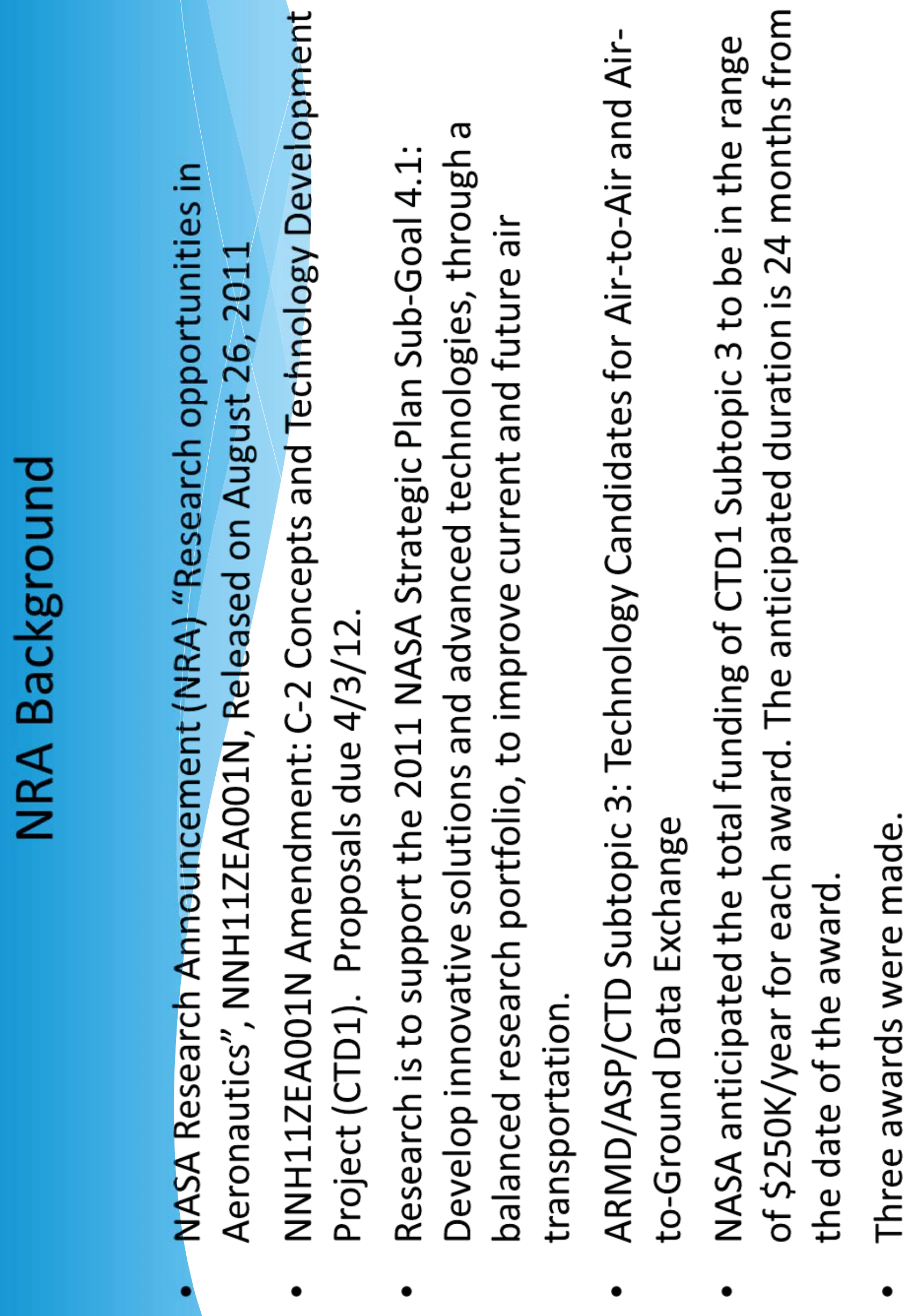




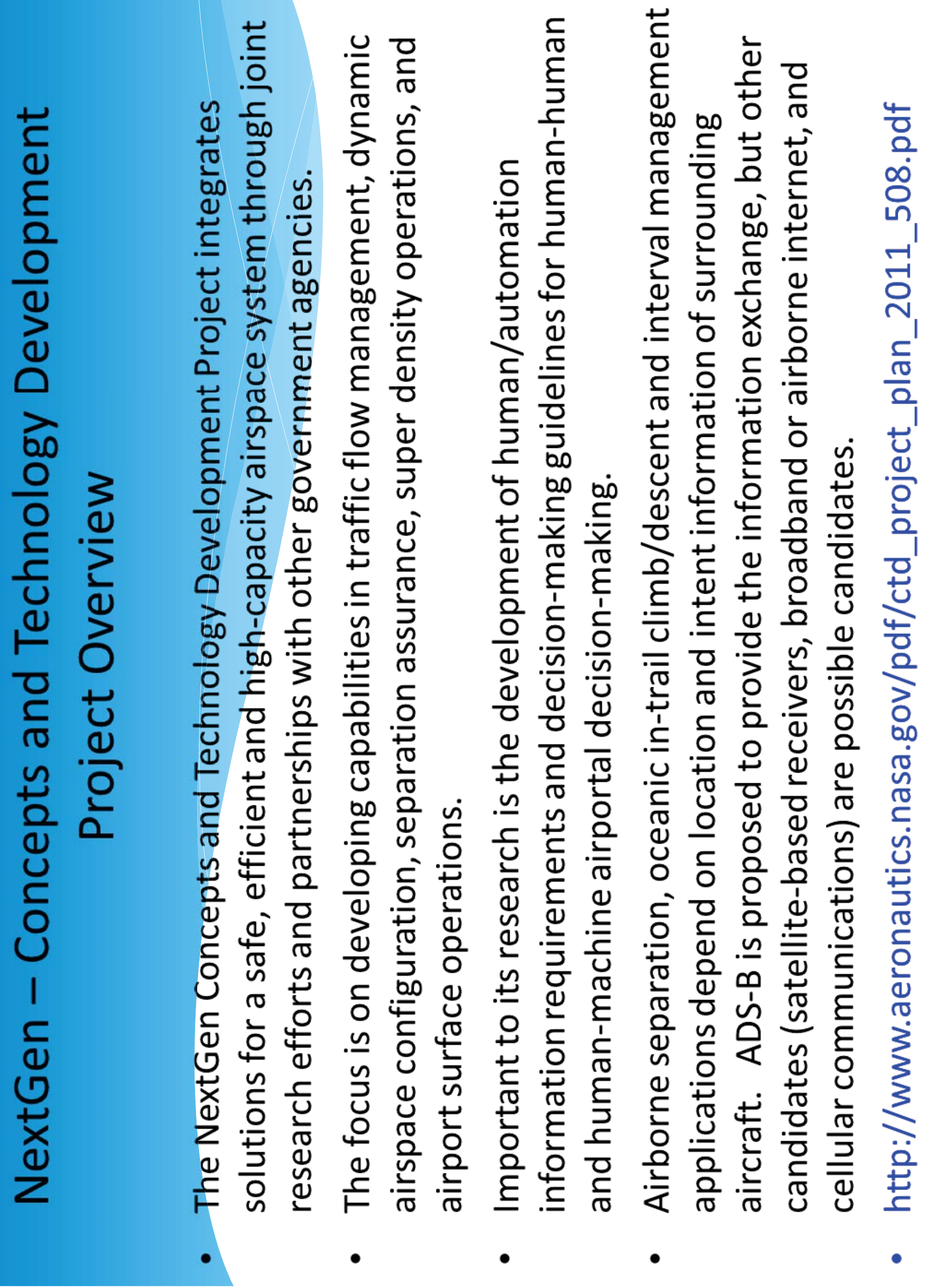




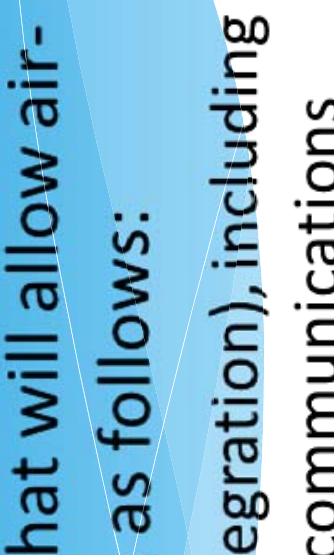

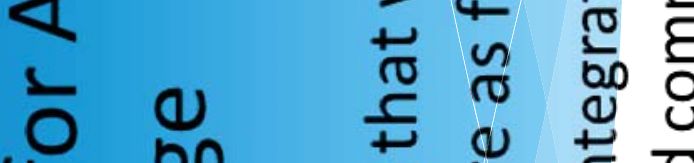

4

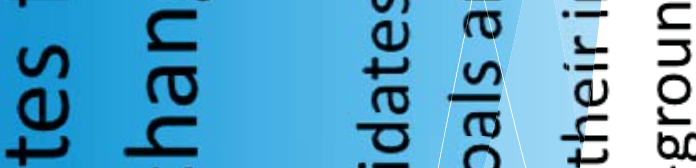

\%

므 뜨

임

ए

\%

$\cup 0$

월

के

으 독

응

ᄃ

ㄴ.

(1)

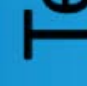

‥

$m$

능

들

○

음 잉

하

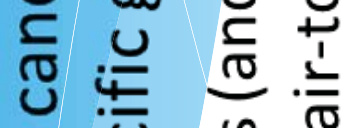

उั

00 윰

응 क

ᄃ

(c)

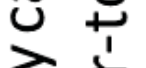

$\pm 6000$

ह $\frac{1}{\frac{1}{0}}$ 응 훈

ᄂ ᄃ

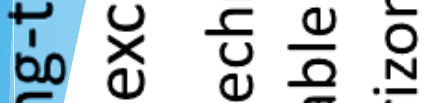

으

三

तृ

कo

히

d

is

$\geq$

造

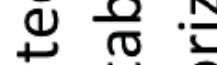

40

के 음

बं山ें

约定

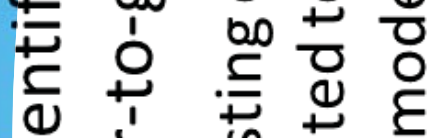

吾.

ज

它

i) 0 政

ఏ) 은

त

बป

웡

$\stackrel{0}{2}$

$\stackrel{\infty}{=} \quad \frac{c}{3} \quad \frac{1}{4}$

흔 $\stackrel{n}{\frac{n}{2}} \quad \frac{d}{6}$

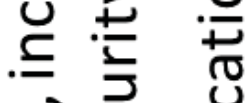

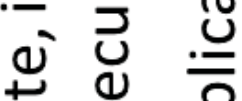

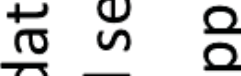

으 므 하

कृ

त خ

ธิ

त

(c) 을

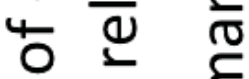

ก

을 는

क

क्ष

ษ. $=\dot{\Xi}$

त

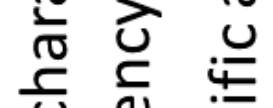

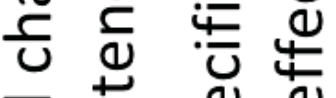

줃

त

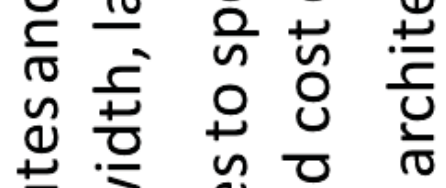

范

ज 0

๖

$\pi$

$\frac{5}{\pi}$

索

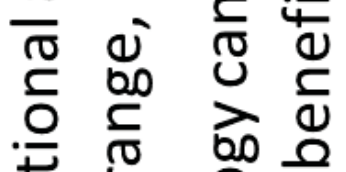

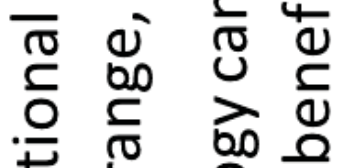

는

논

둥

$\stackrel{+}{\frac{1}{5}}$

站

든

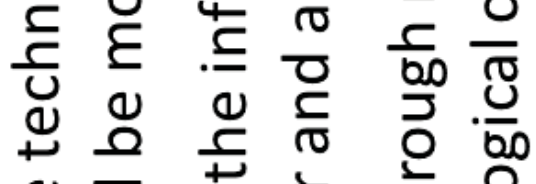

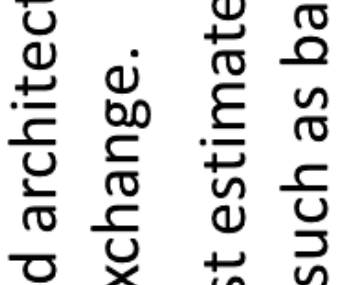

장

त 0 Oे

ญ ᄃ

艺

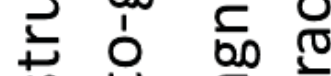

究

은.

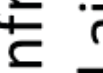

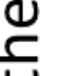

$\stackrel{\overline{\bar{y}}}{\overline{3}}$

t:

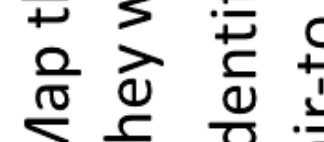

वे 웡

$\dot{m}+\dot{\sigma}$

N

N

용

व

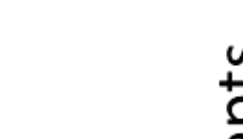

范

व

ธิ

है ত

(1) บ

๘

들 응

ह ํㅡㄹ

는

त

Ð $\frac{1}{0}$

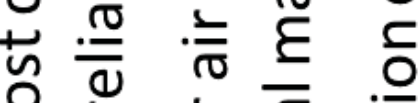

บั

$\geq \frac{1}{\pi}$ 元

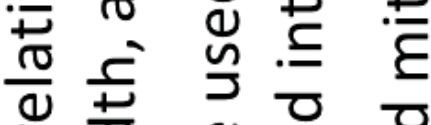

응 응

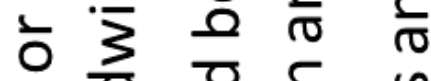

जं 을 은

ब

บ 든

哭

응 :

을 巳

ᄃ ํํㅇ

ช 은

$\pm \frac{\overline{1}}{\sigma} \frac{1}{\sigma}$

ป d

ข

도 竞 吾

3 음

으드 은

든 들

이일 으

는 ह

드도 을 으

넌 जु응

으 뽄 운 으

ن

N 
苋 $\frac{\overline{0}}{0} \overline{0}$

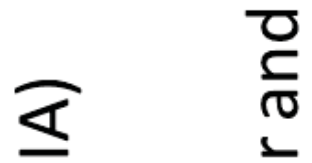

$\frac{5}{50}$

这

$\bar{z}$

,

$\stackrel{\mathscr{\pi}}{\sim}$

这

$\frac{1}{2}$

용

ভ

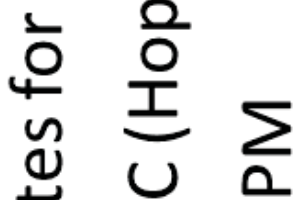

可

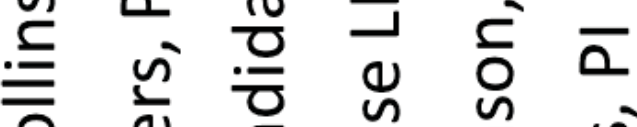

范

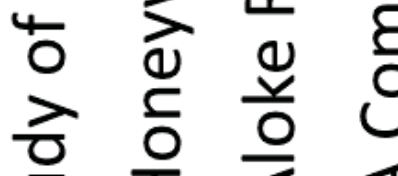

노 준

出 1

Uั

थै जे vं

बे

3

จิ

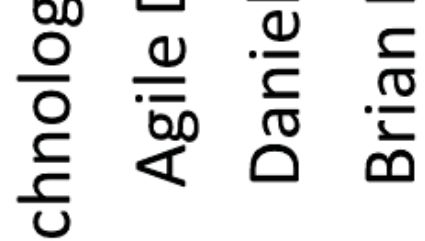

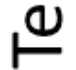




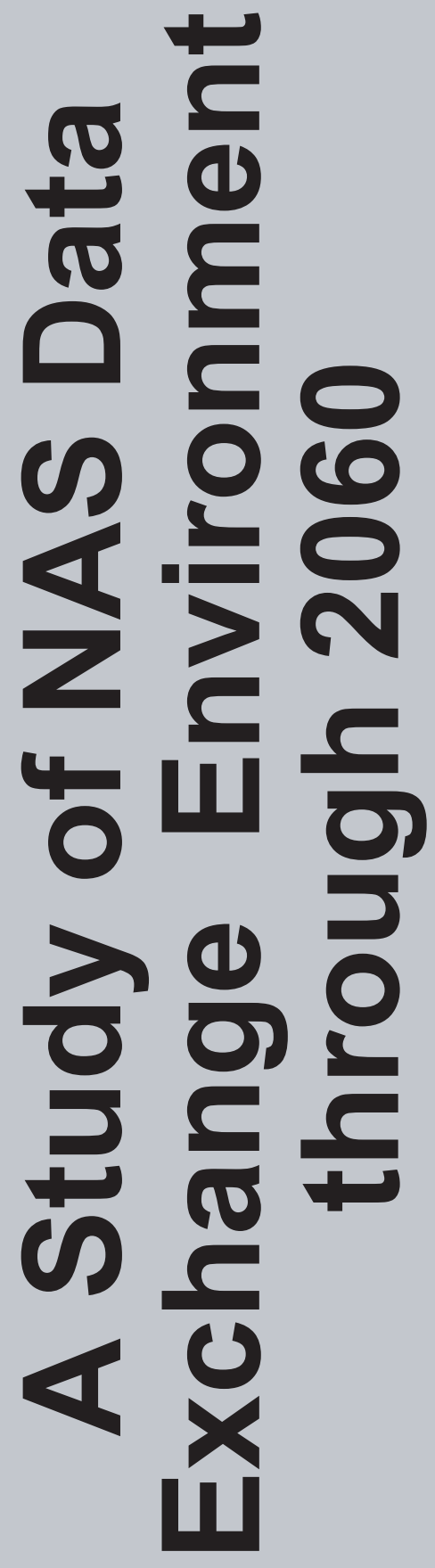

$\frac{1}{8}$ 

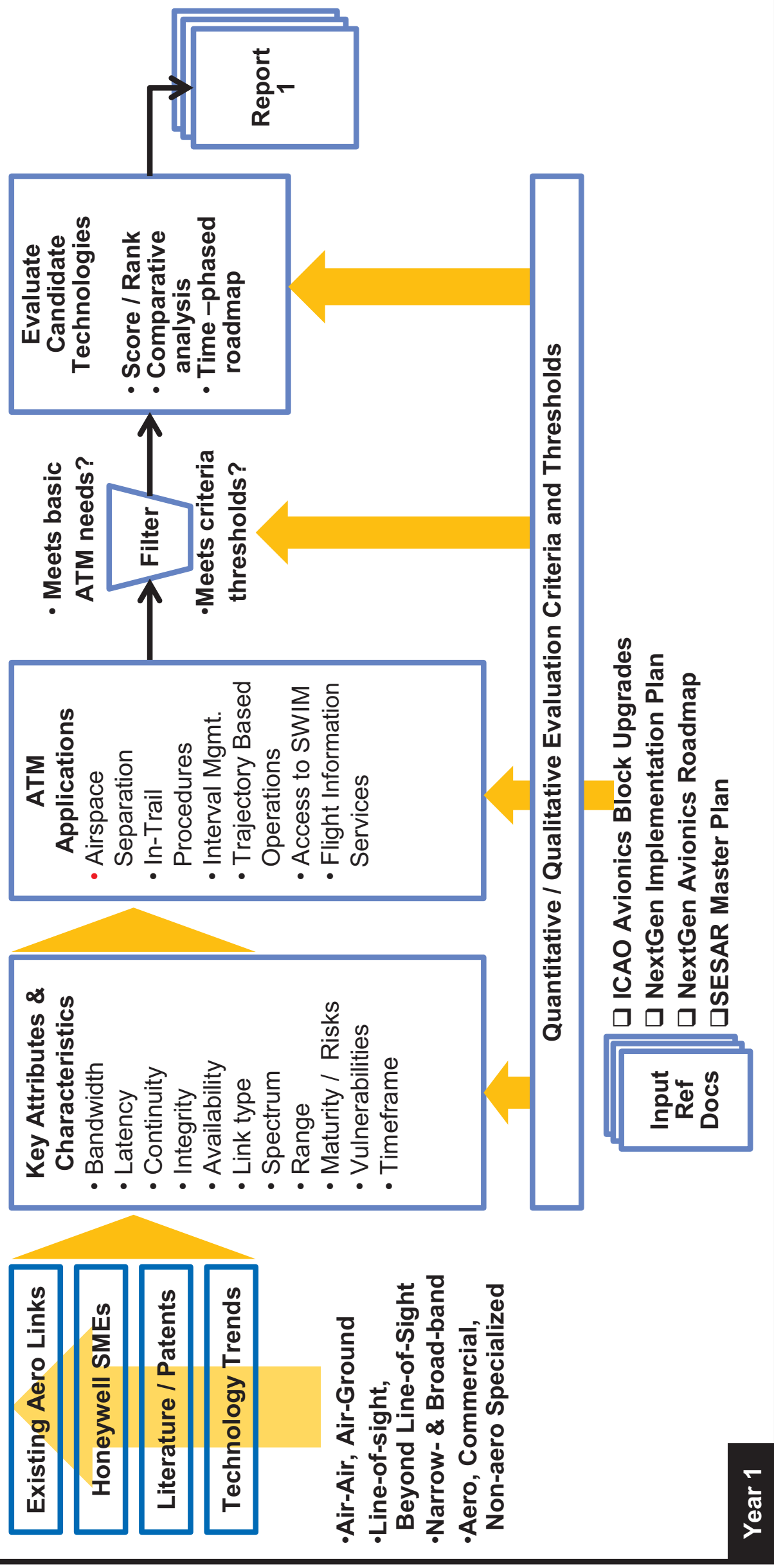


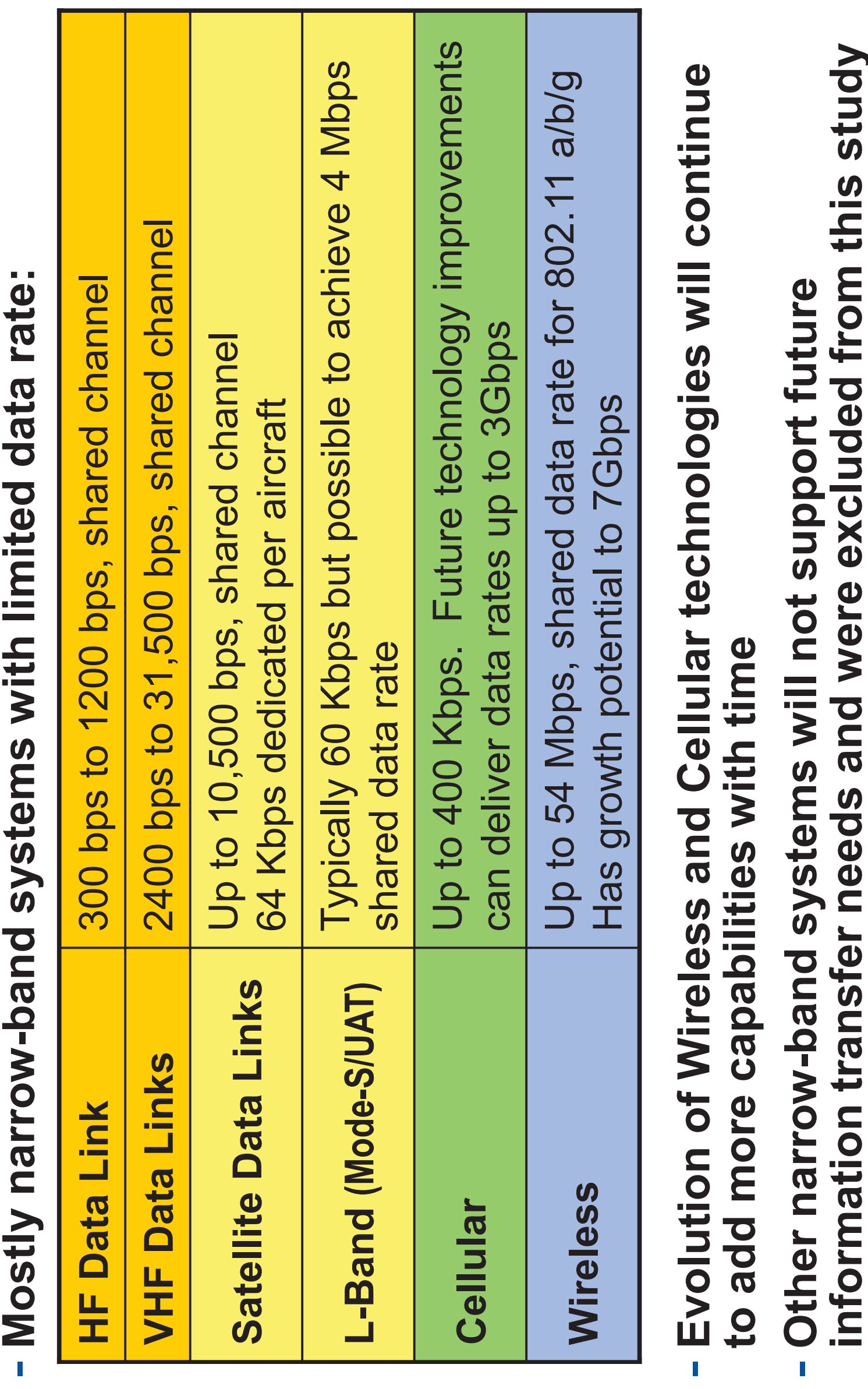




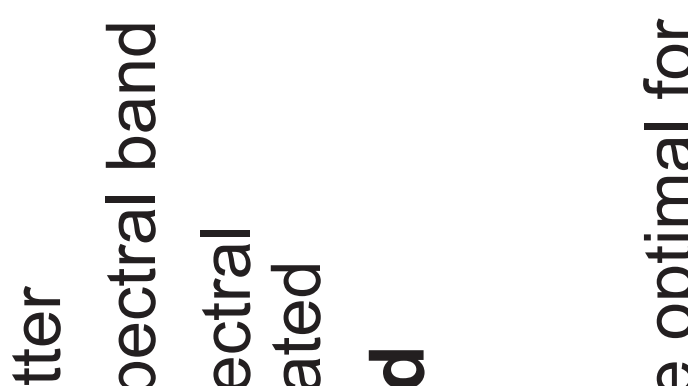

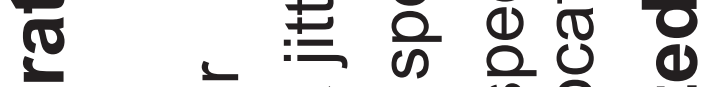

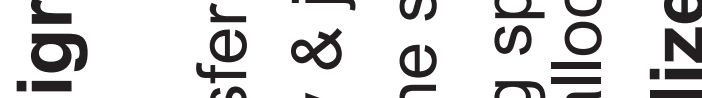

ह

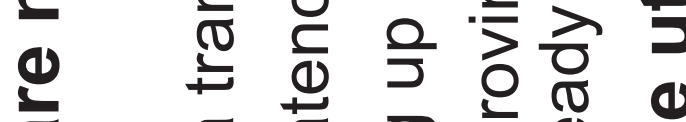

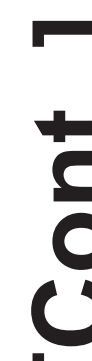

$\pi$

1

요

을

10

2

c

c

$+$

$\Phi$

त

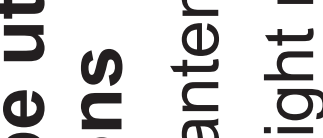

(s)

응 $\frac{\pi}{\varepsilon}$

至京

范 予

๕)

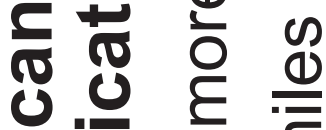

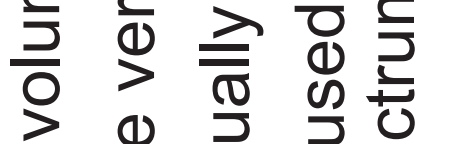

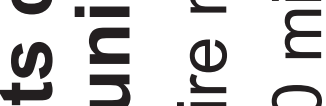

들 흘 웅

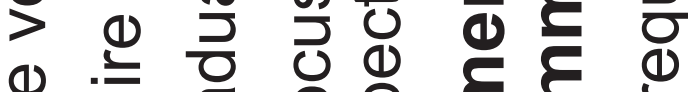

ब.

6) 0 \&

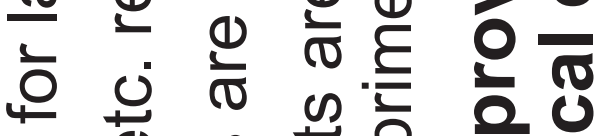

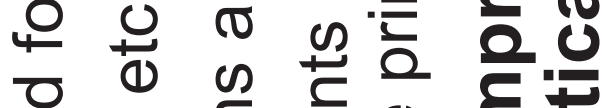

ᄃ

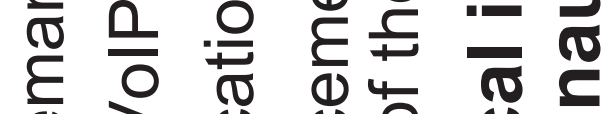

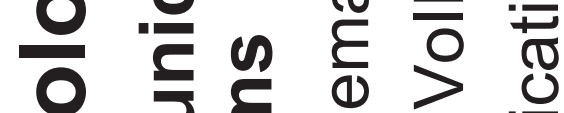

$\pi$

응

亨

œ

$\frac{\mathscr{Q}}{\mathbb{N}}$

$\frac{\Phi}{\omega} \frac{\varepsilon}{\omega}$

के की

()

ఫ

तั

$m$

$\frac{\searrow}{\sqrt{2}}$

ণ্তে

i

0

(ฮ) 둥

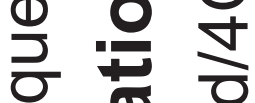

(1)

느 0

닌

(1)

을 당

ఠิ

तั

음

ธ

은

$m$

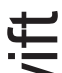

क

$\div \quad 0$ ㄴ

$+$

E 는

1)

入

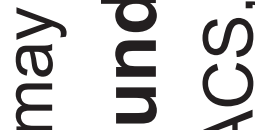

$\sum$

$\equiv$

10

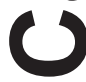

$\geqslant$ क

है

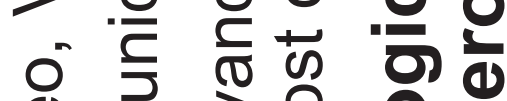

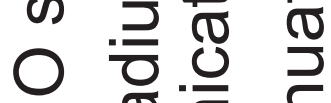

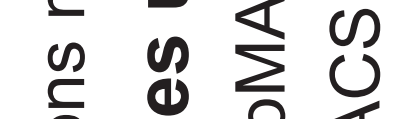

$\bar{\alpha}$

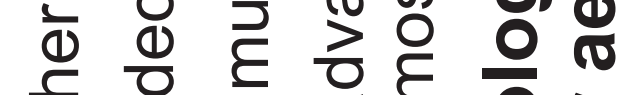

$\sum$ 즌

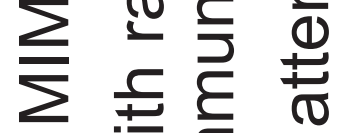

이 \)

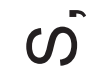

ह है

F

0 内 을

응

ᄃ

d

은 $\square$

山

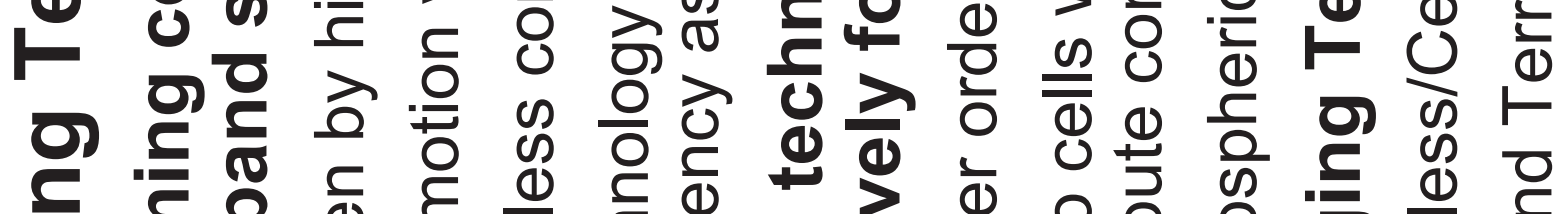

0

트응

(2) 80

(1) ह

๕

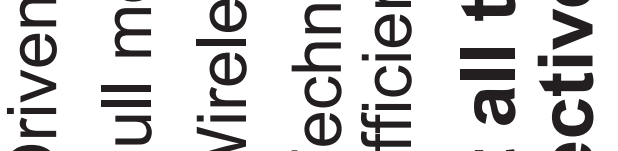

๕)

u 을 요

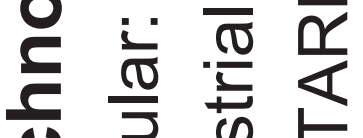

U

농

눈

II 


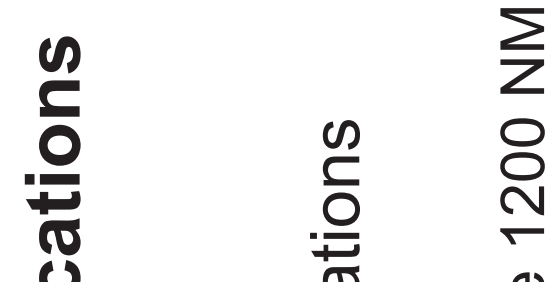

ò

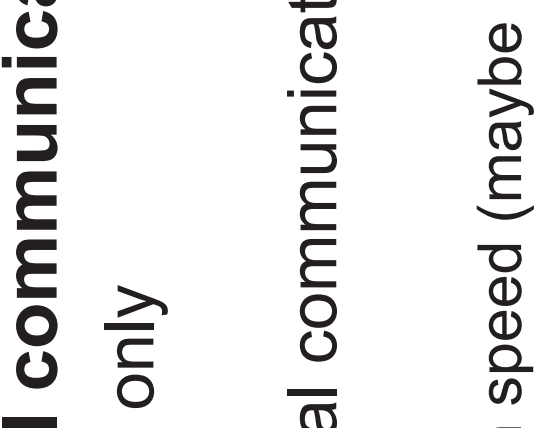

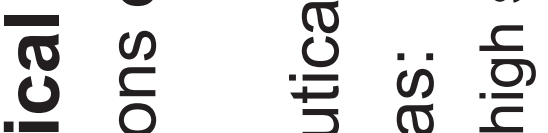

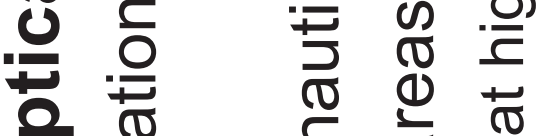

2.

()

U है है

() 0 ह $£$ ह ह

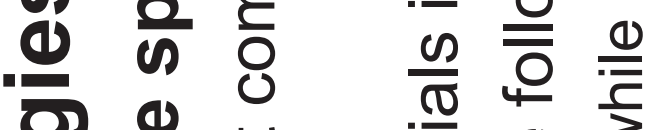

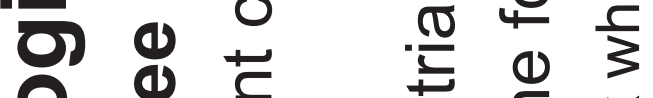

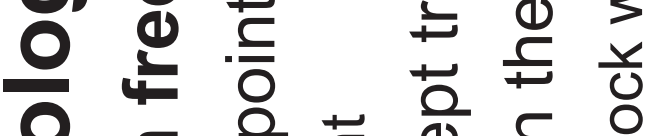

$\frac{\infty}{\frac{N}{0}}$

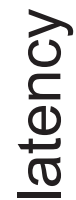

")

$\mathcal{\complement}$

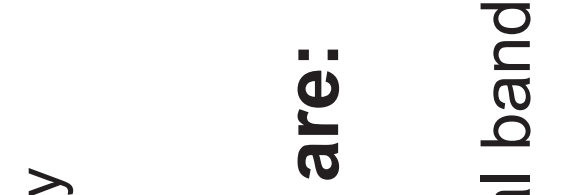

E 드으

宅 $=\frac{\bar{\sigma}}{\bar{\sigma}}$

ए $\varepsilon \stackrel{4}{\circ}$

(1) 1 .

J

ฮั

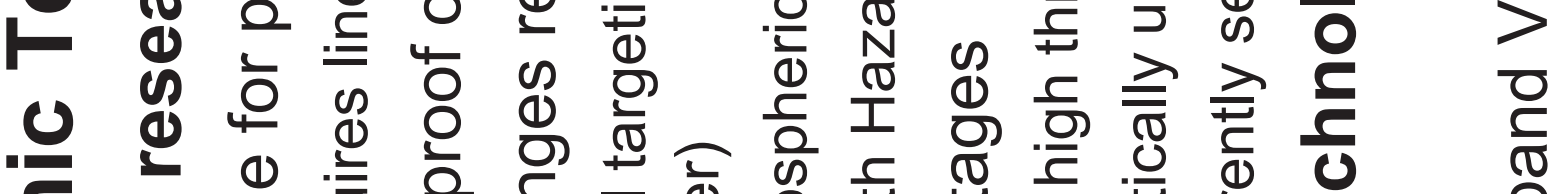

U ह

$\stackrel{0}{\stackrel{0}{\Phi}} \stackrel{0}{\frac{0}{0}}$

는

永

\%

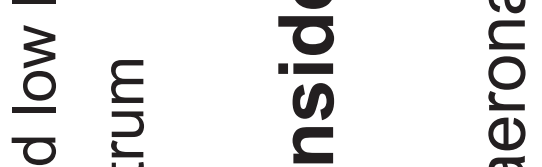

든당

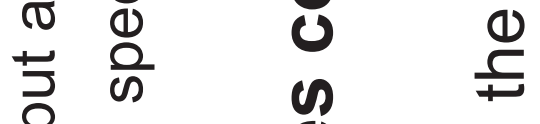

음 Ð Ð

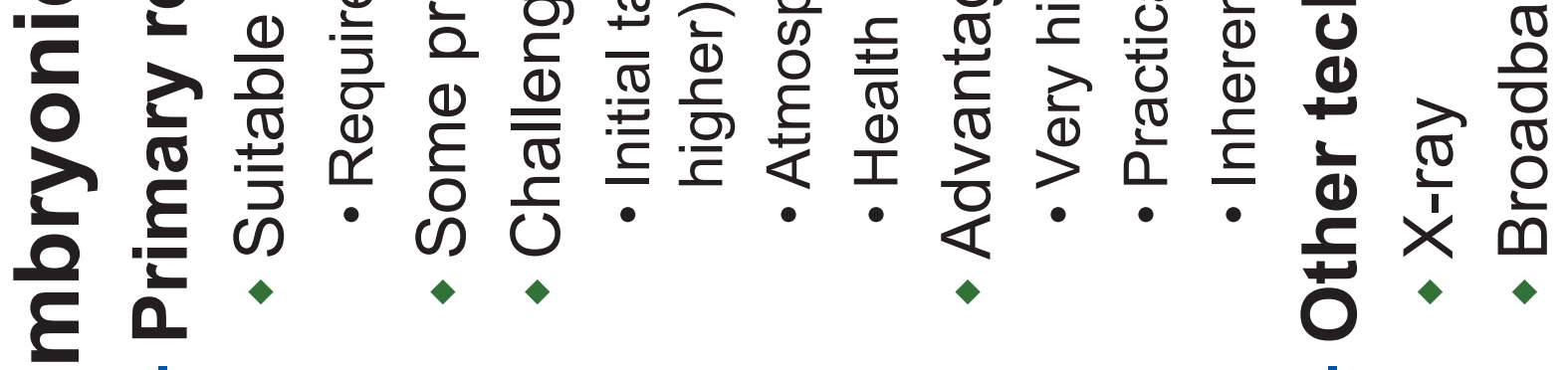

(1)

U 


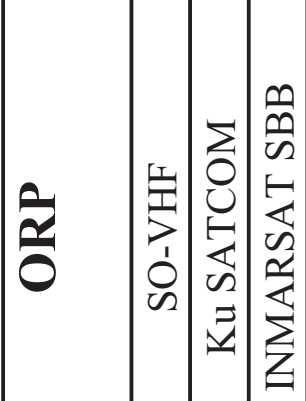

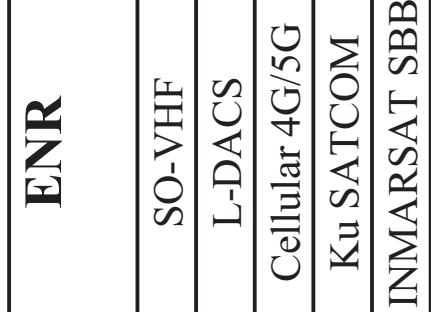

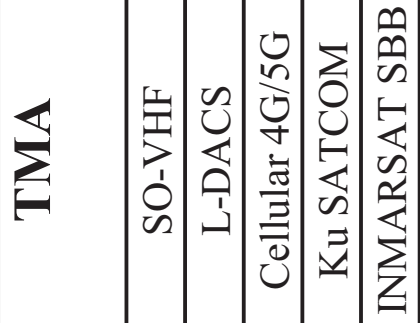

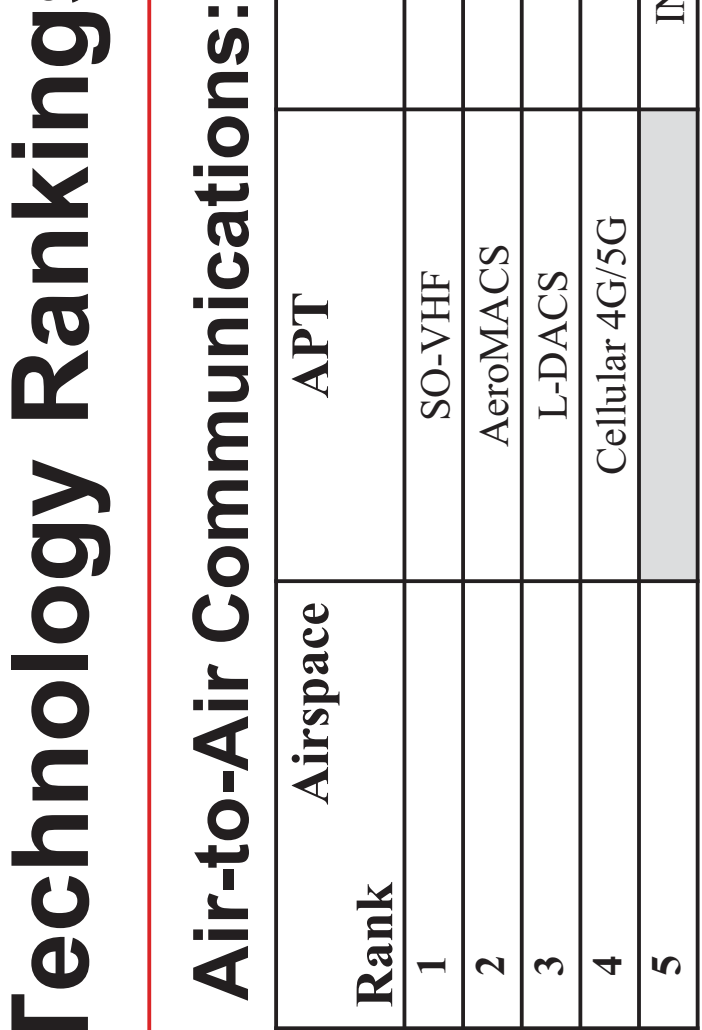

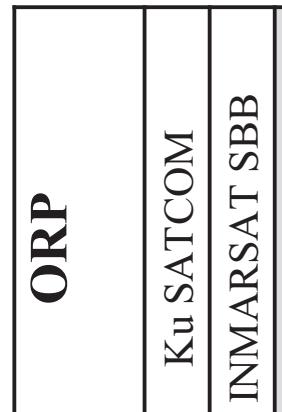

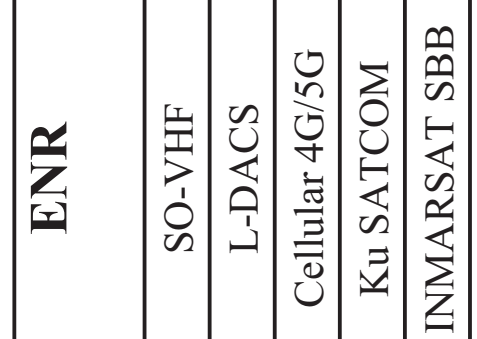

(1)

0

हE

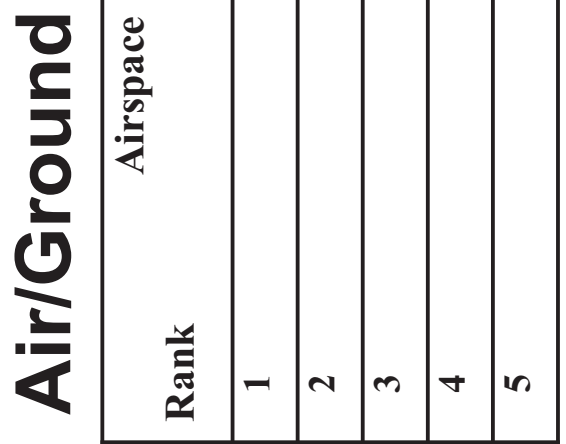

0 角

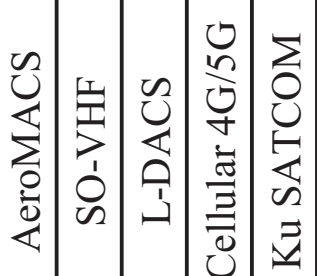

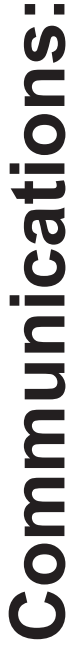

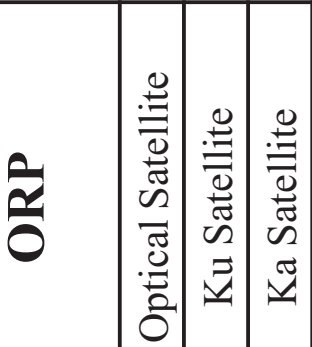

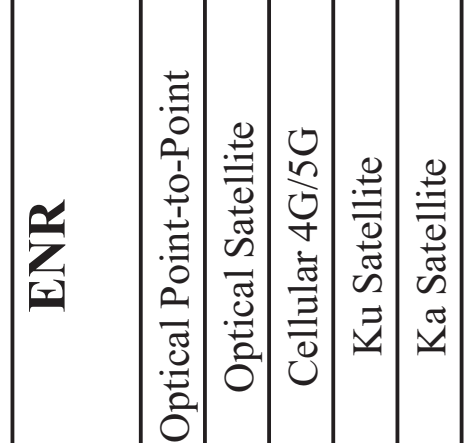

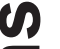

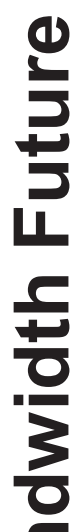

E

ดิ

E

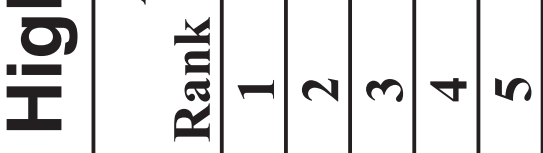




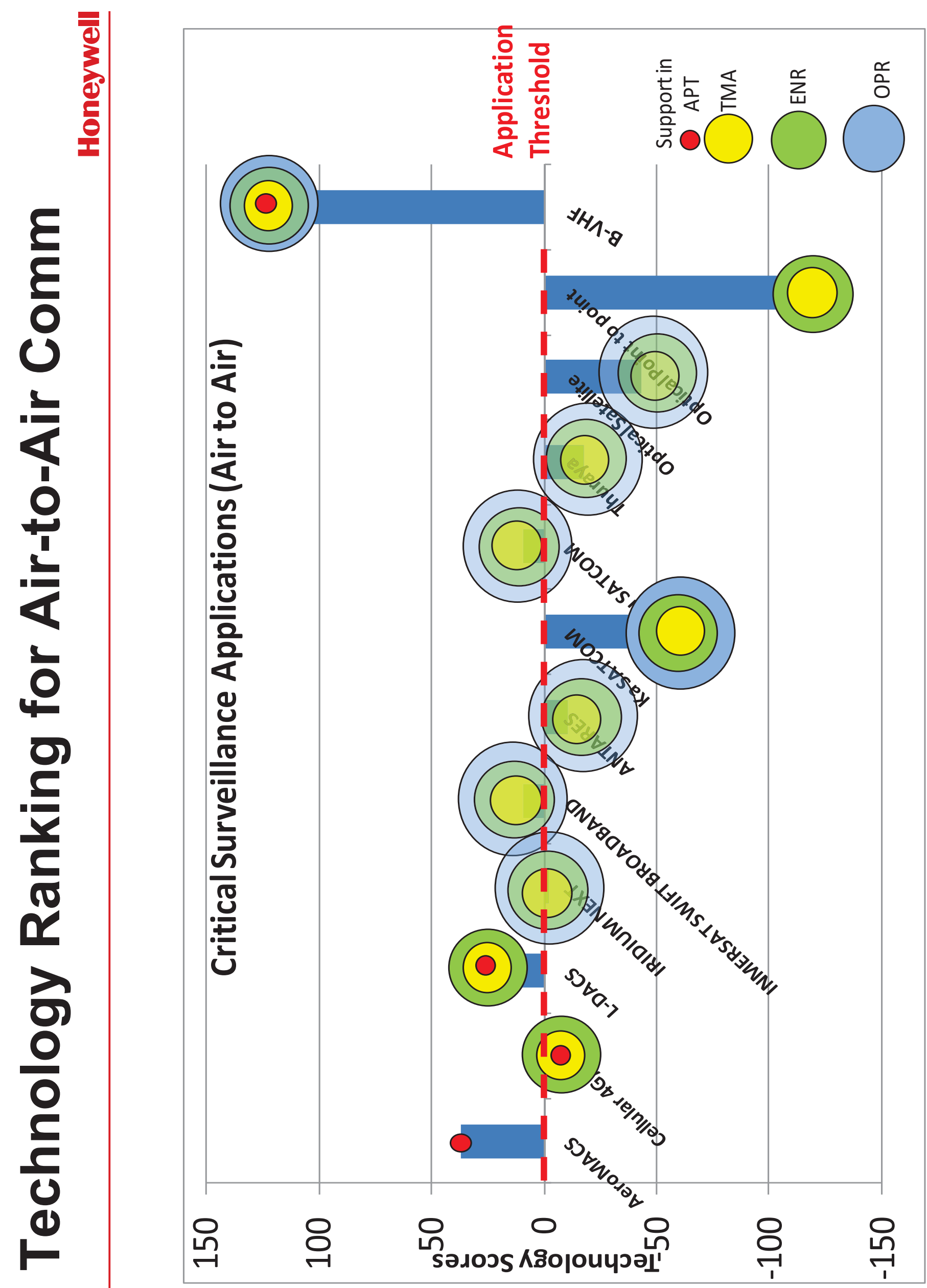




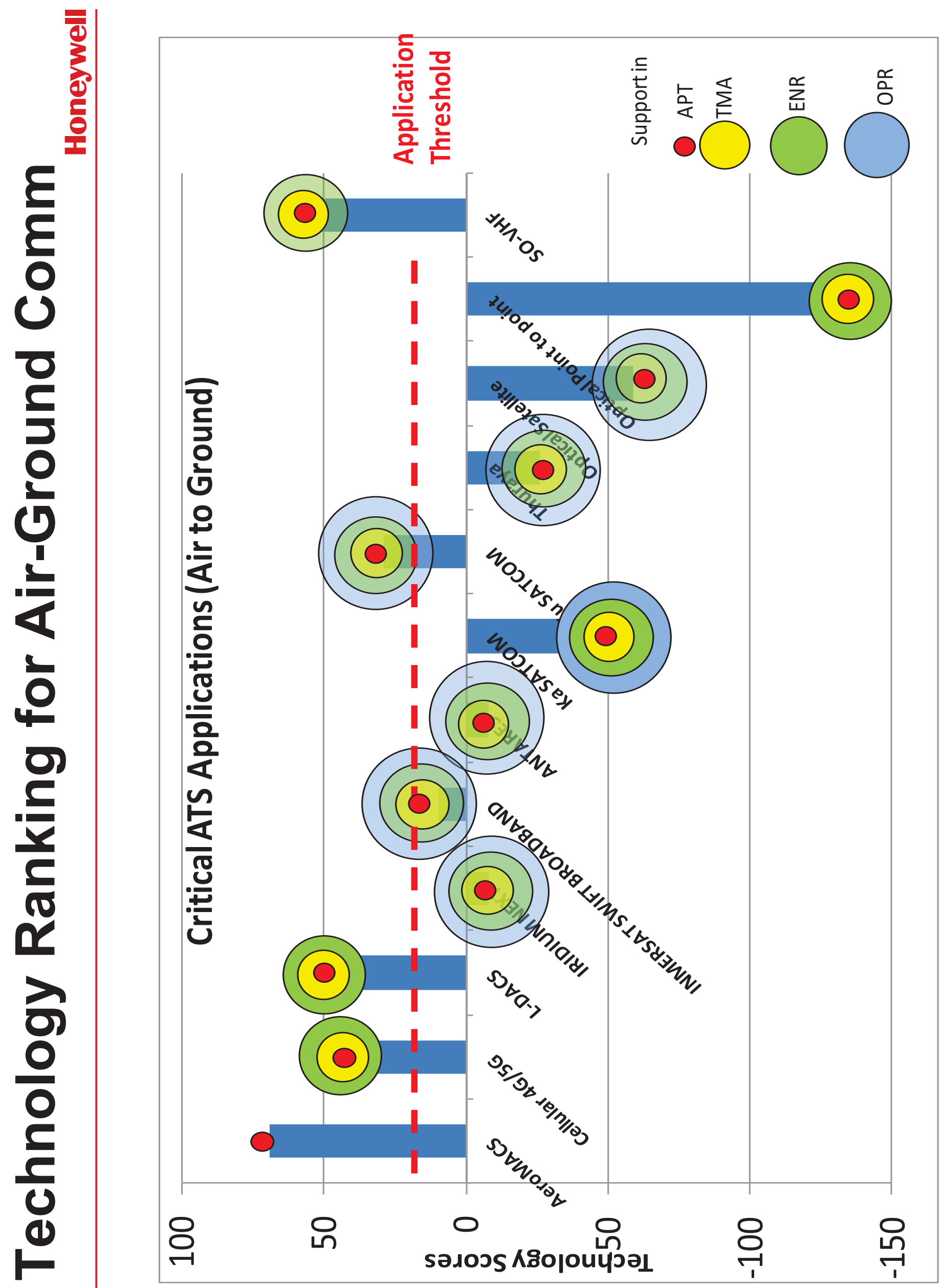




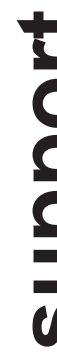

0

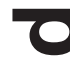

(1)

E

음

1

$-1$

(S)

0

0

$\overline{1} \frac{\infty}{0}$

30

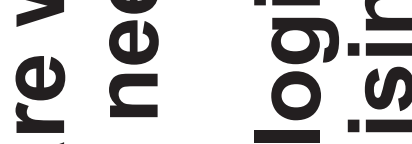

( 5

n 0

언

응

은

을 늘 을

을

$\pm$

o

도

(1)

인

$\Phi$

E

ш

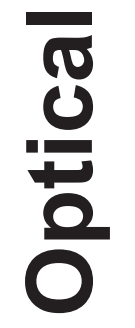

(a)

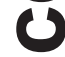

10

0

(a)

(b)

עL

in

ฮ

O

달

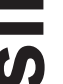

을

등

응 응

으노

고음

으 잉

ह

흐음

으ㅇㅡㅗ

든

บัญ

O

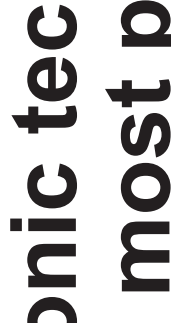

0

$2 \infty$

(1)

(1)

(1)

$E$

(1)

흔

으 궁

= 엉

F

3

os

둥

을

흠

응

( )

命

б)

으

온

임

ํㅡㅇ

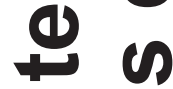

ช

은 옹

(1)

$>$ \%

○

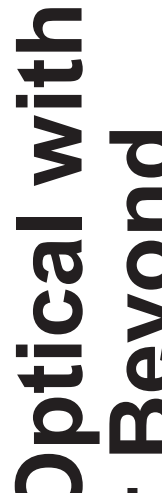

( 1

(4) 0

(1) 0

00

क क

$\Phi \geqslant$

(들

토

O)

엉

동

으론

ह 3

은

웅

등응

응

흔우

긍

क क

웜

은

온

入西

王以之

○

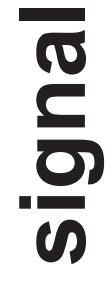

도

$\omega$

(1)

o) 0

$=\frac{0}{\infty} \frac{\infty}{\infty}$

e 10

( 00

(1) E E

$E$
$\theta$

o) 0

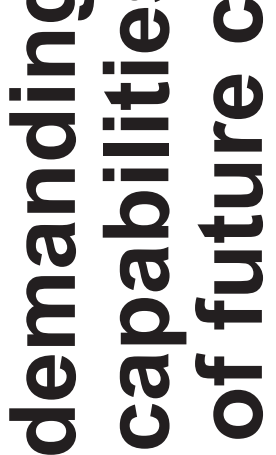

( ) 1

हE ह (1)

$=0$

(1) (1)

- 03

(0)

《द 


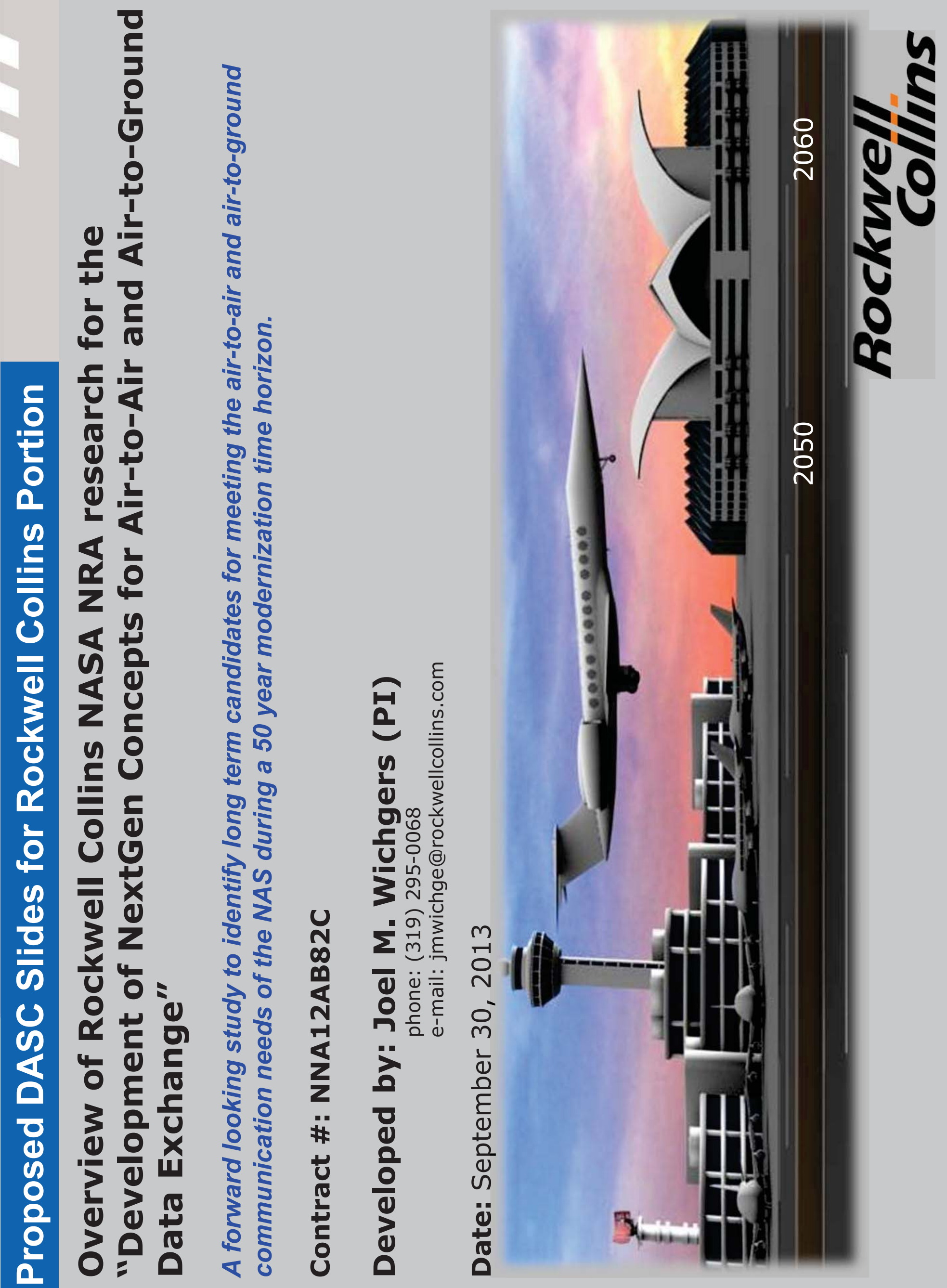




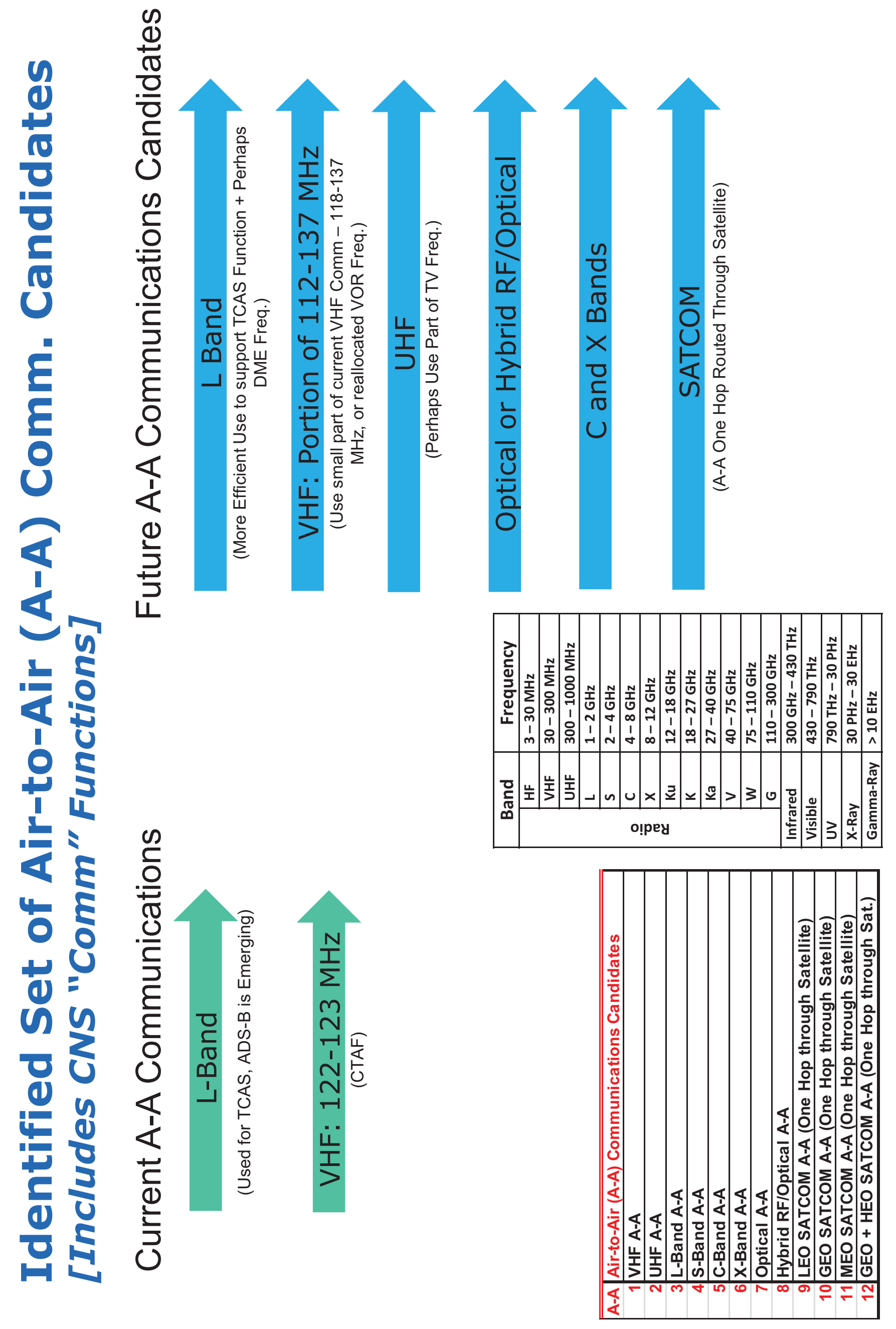




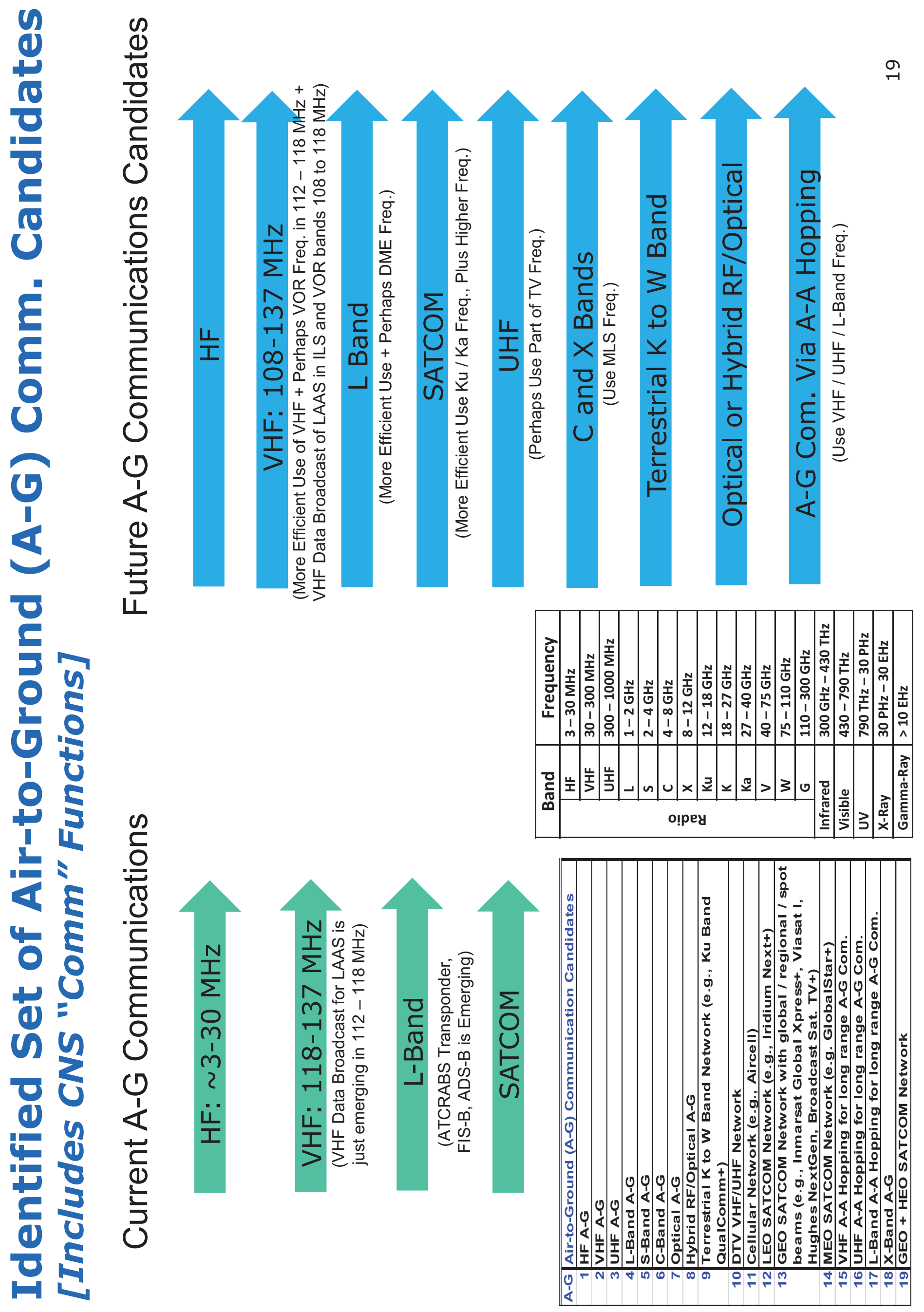




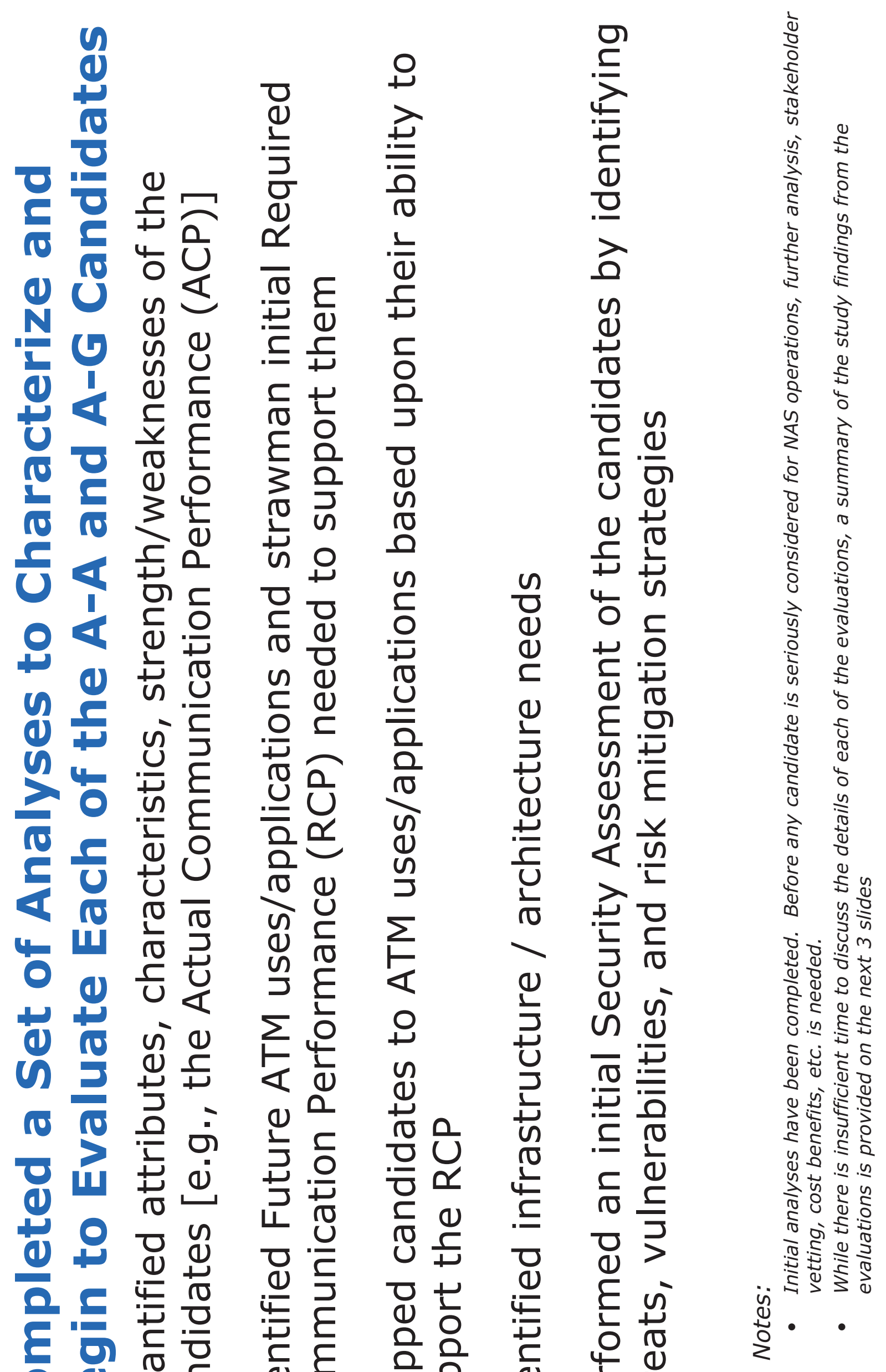




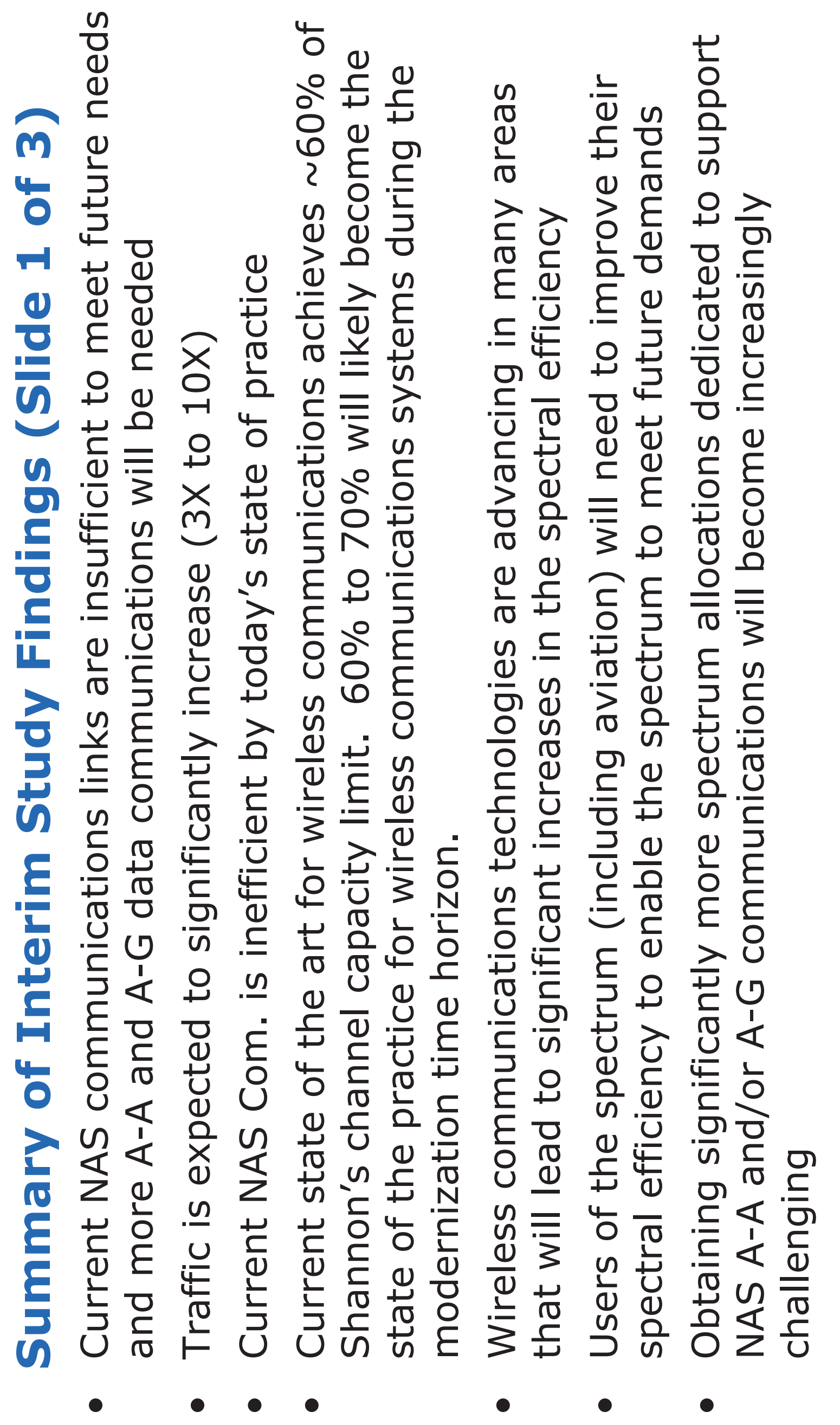




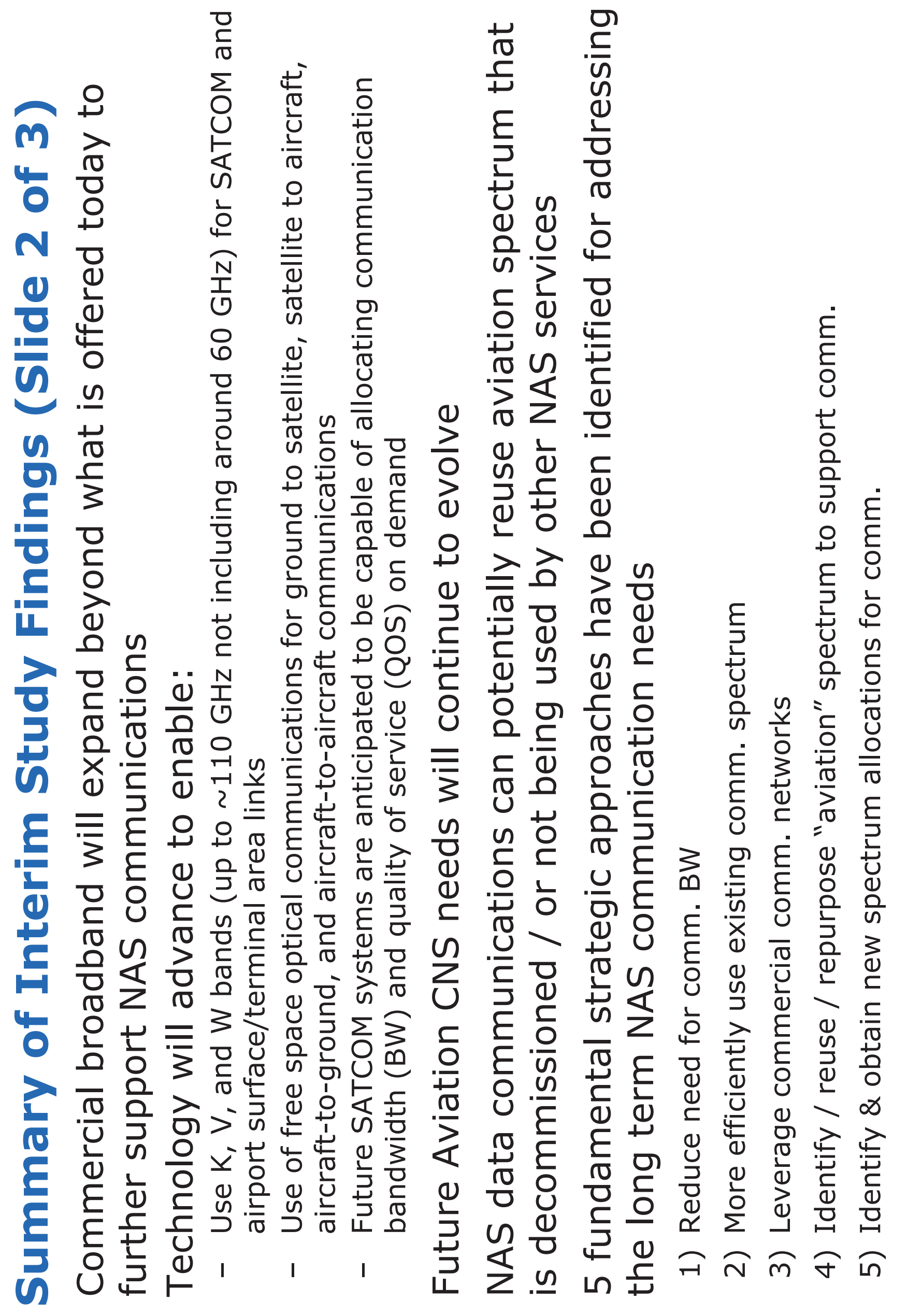




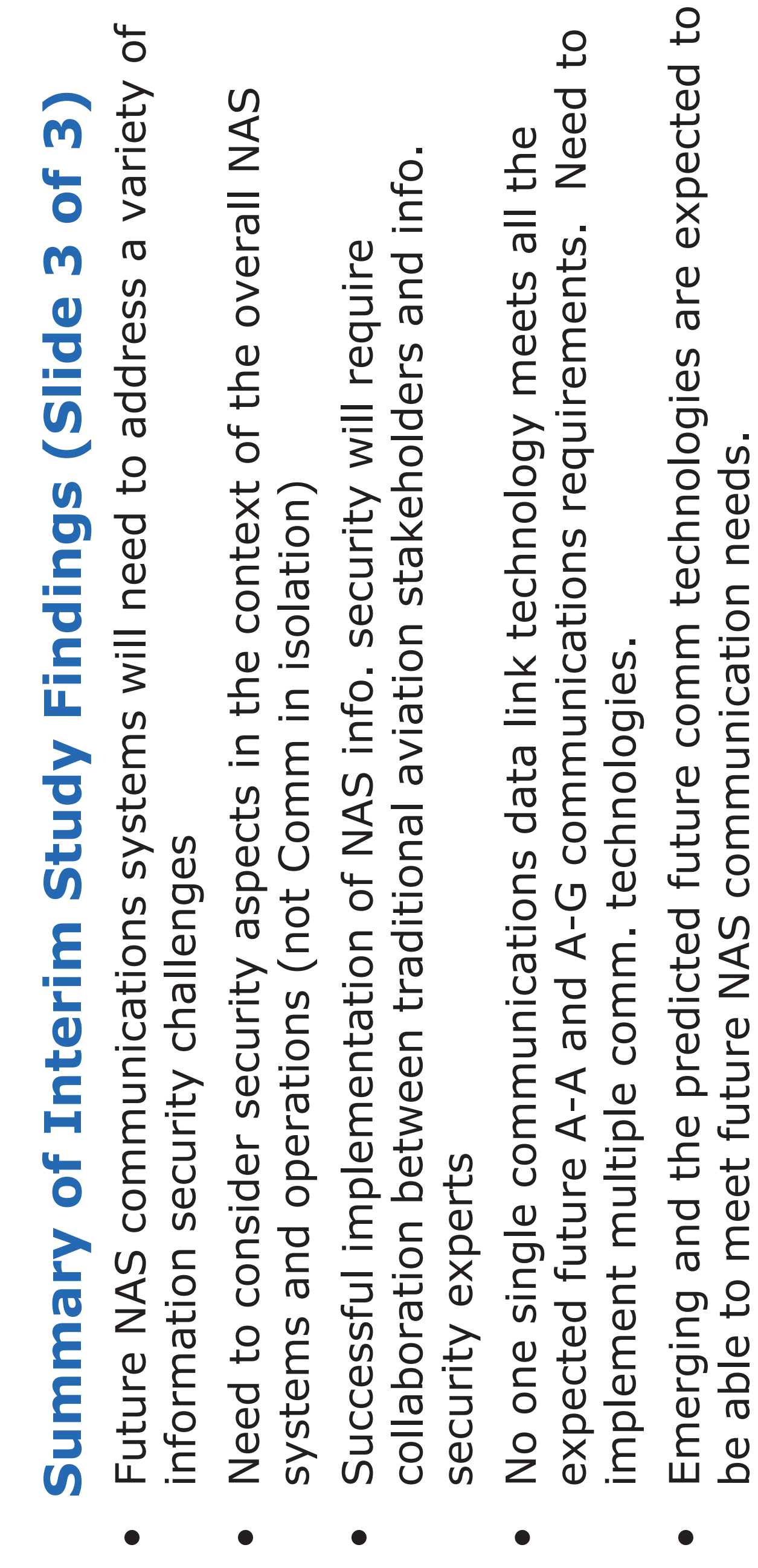


이 니 Is (f)

니 $02 \geqslant$

니 $\rightarrow$ 잔

c) या हा

Q1

니

(ii)

c)

c)

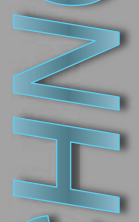

c)

if

a

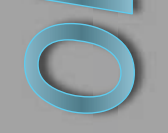

2

니

C)

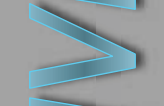

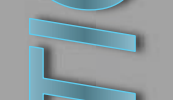

is

(c)

III $\overrightarrow{~ ब ा ~}$

(c)

III]

1
1

c)

(f)

Q

긴

स वे

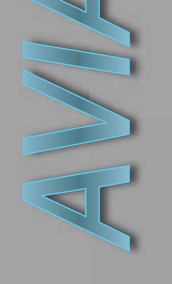

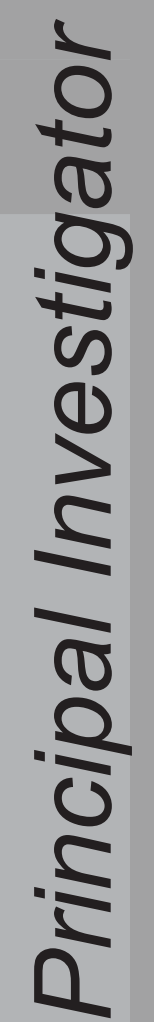

1

\& 0

$\frac{\sqrt{\sigma}}{\frac{\pi}{0}}$

I 1

离 


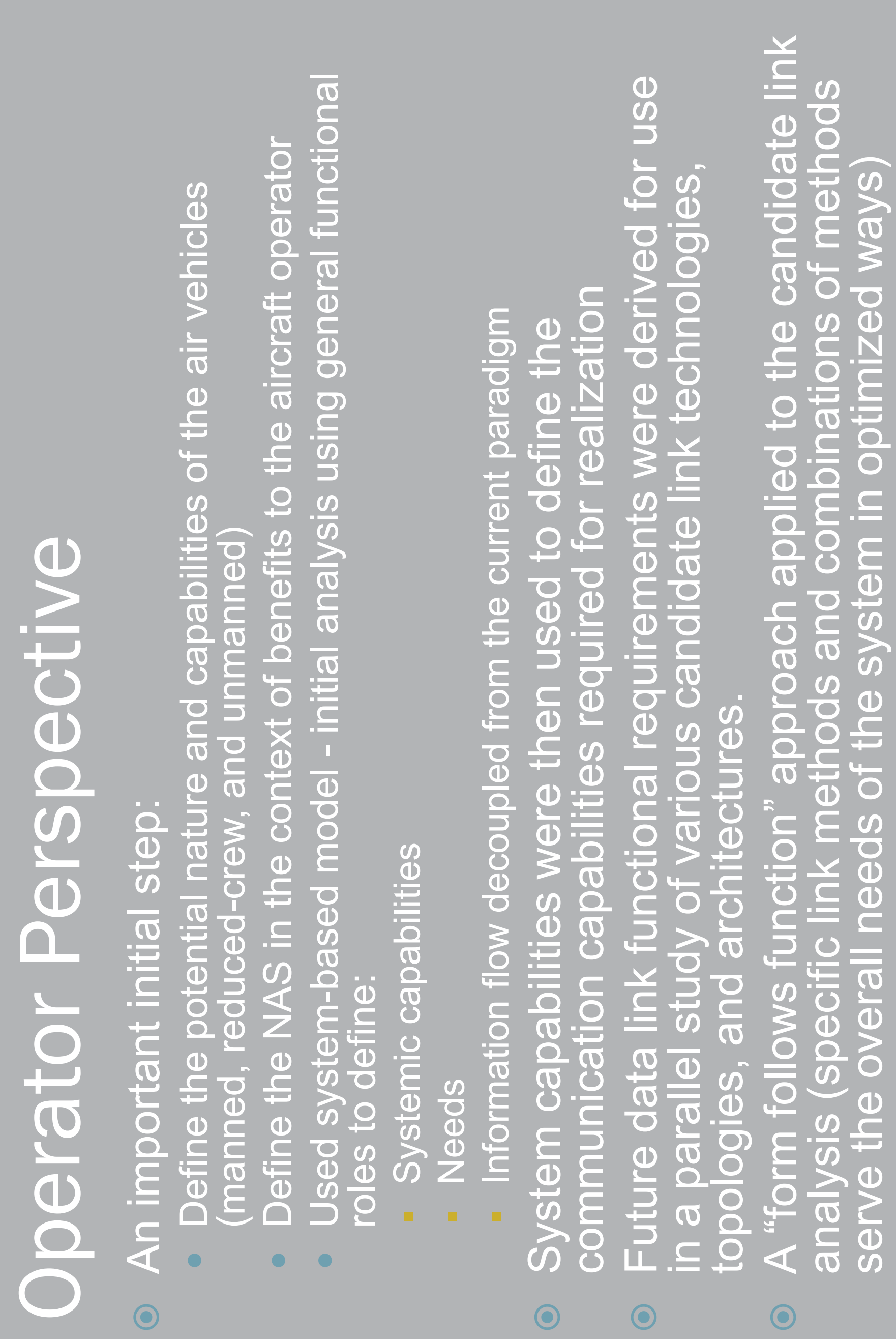




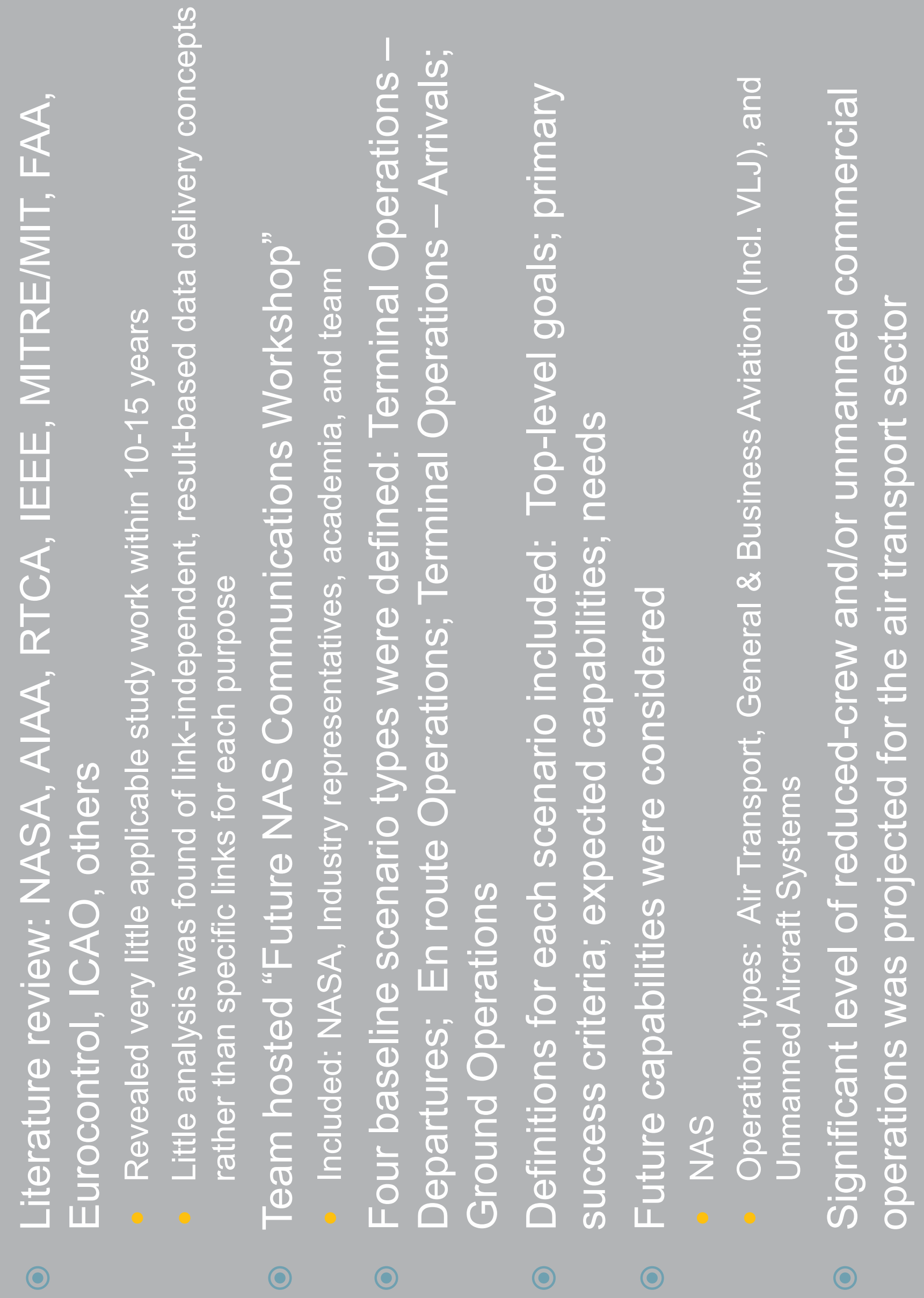




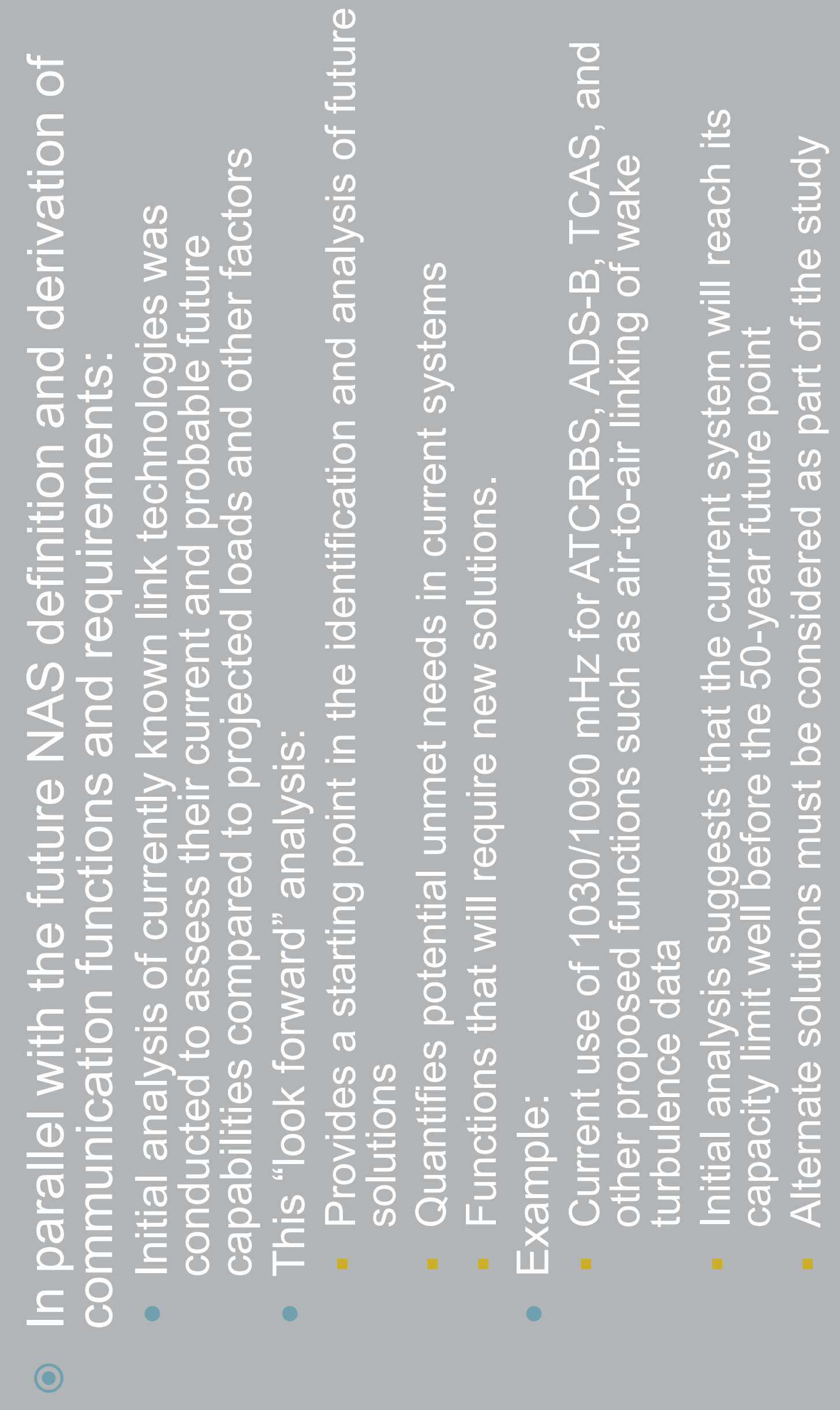


$\frac{1}{2}$

$\frac{\text { 등 }}{\frac{1}{20}}$

일

ros

(1)

(1)

1

(

กี

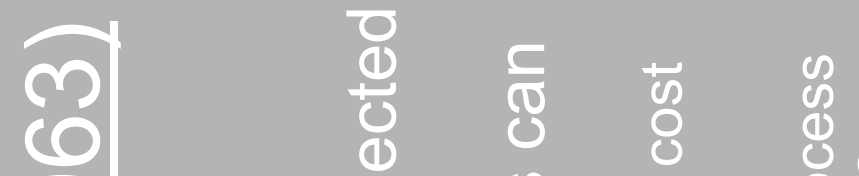

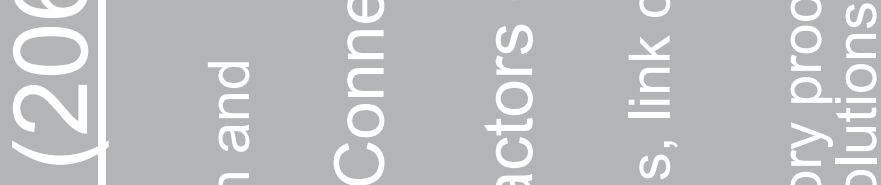

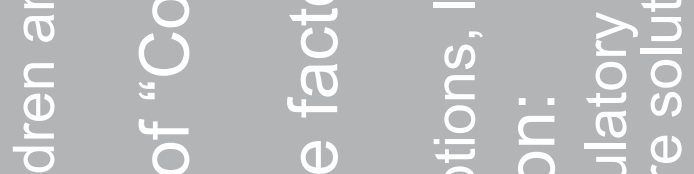

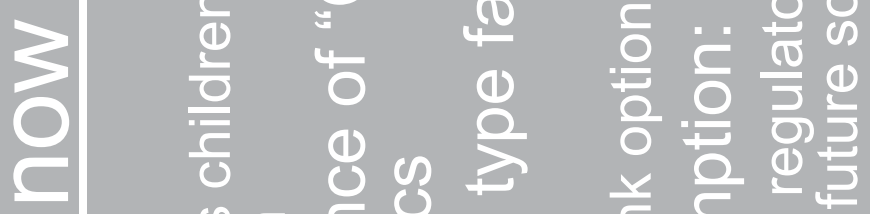

i

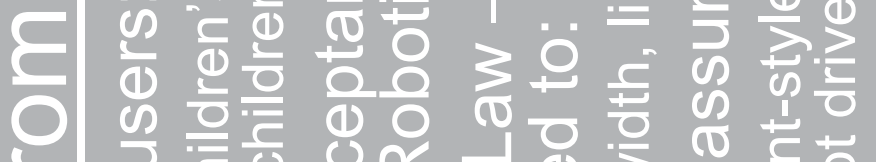

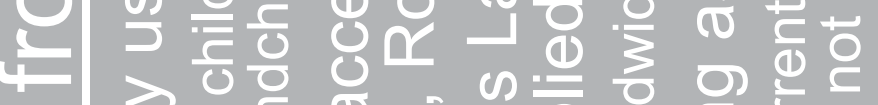

는 능

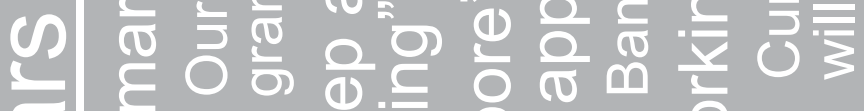

ब

(1)

(

()

(2)

(?)

( )

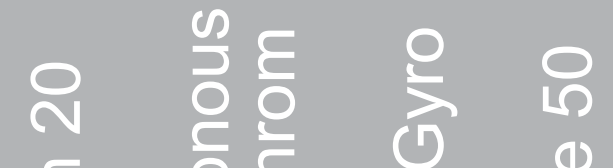

당 일

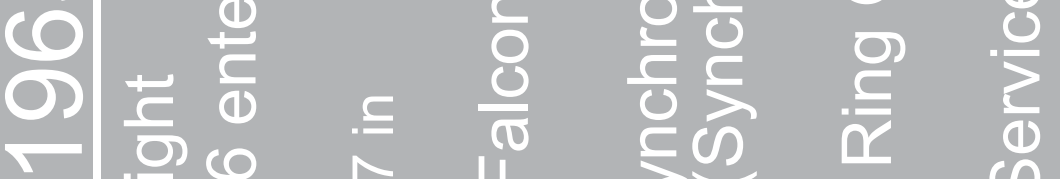

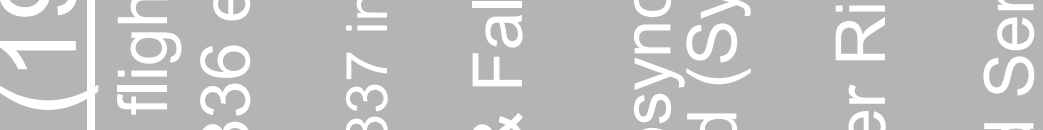

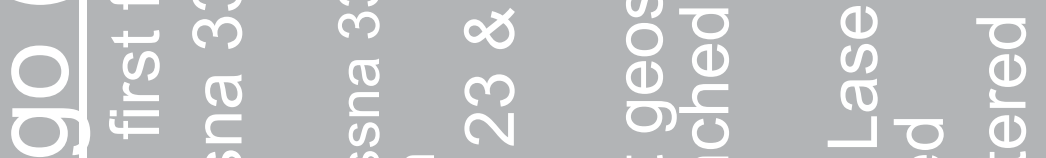

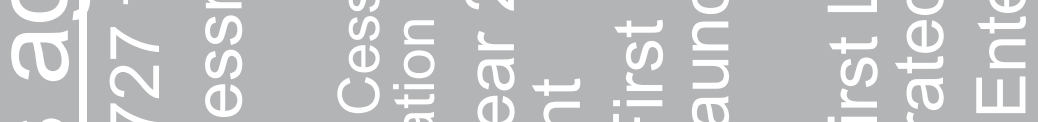

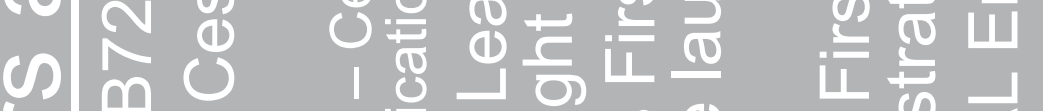

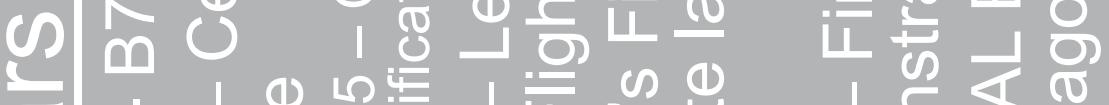

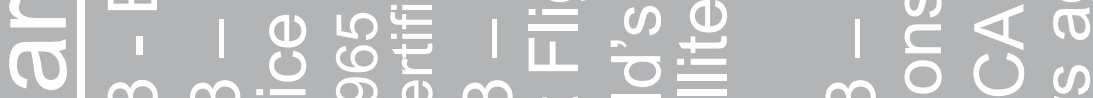

(1)

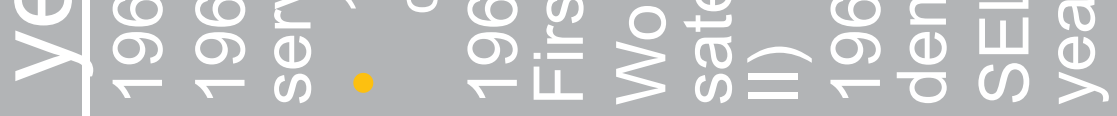

ค

$\infty$

L) $\odot$

(2)

(

(2)

(2) 


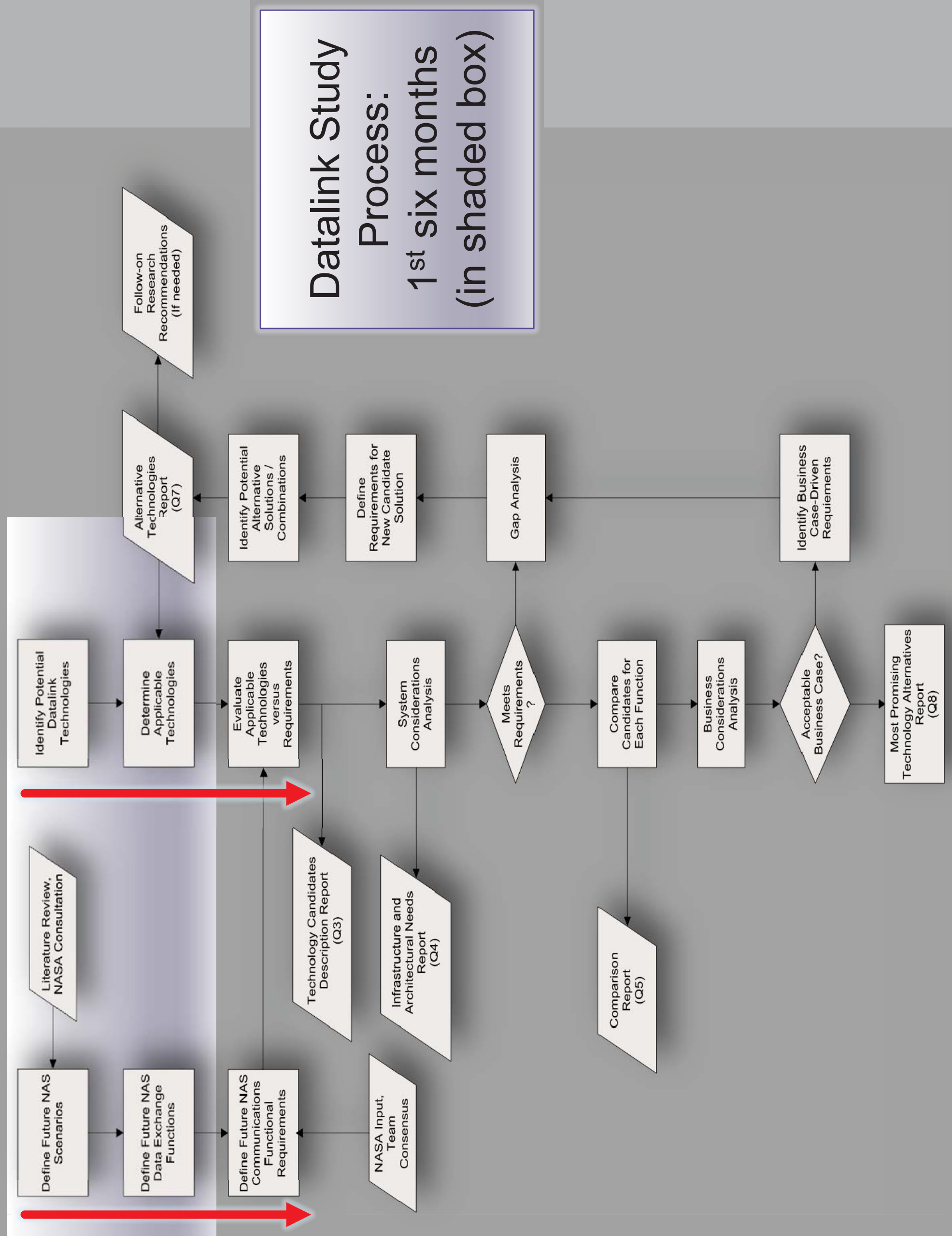




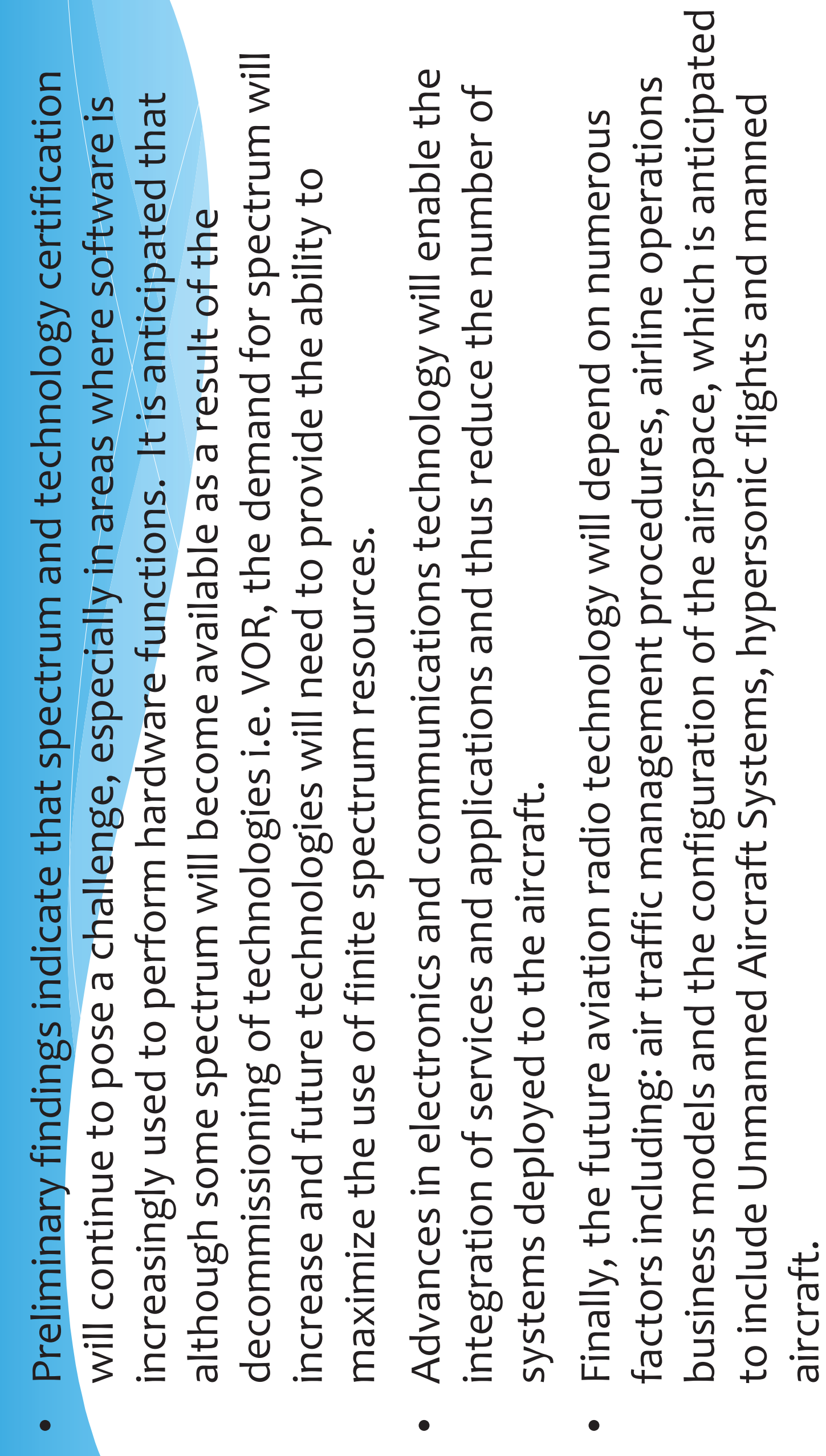

